


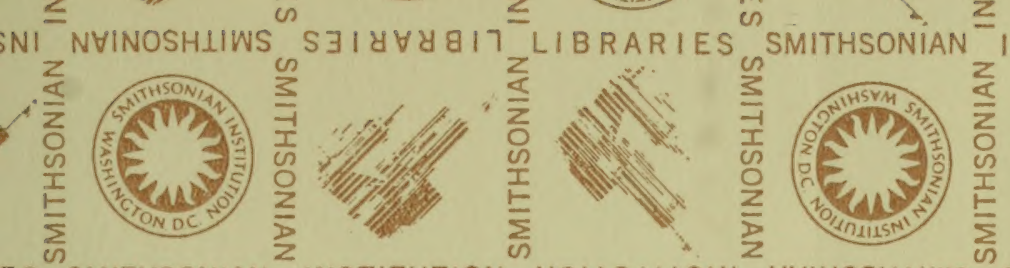

ES SMITHSONIAN

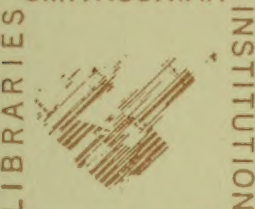

NI NHINOSHLIWS

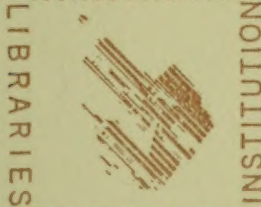

ES SMITHSONIAN
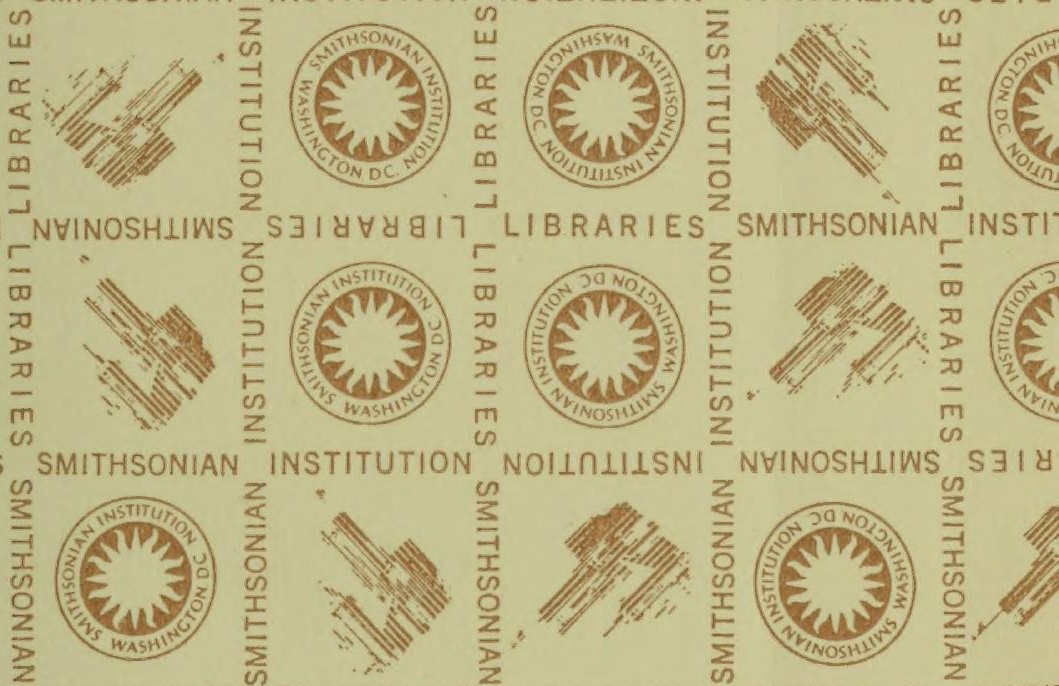

SMITHSONIAN
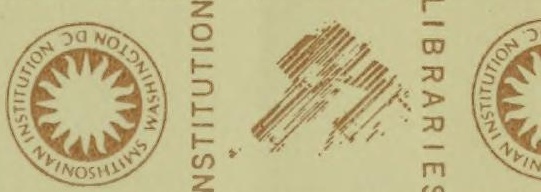

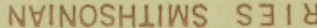
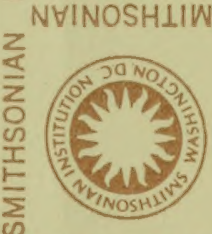

$\frac{n}{3}$
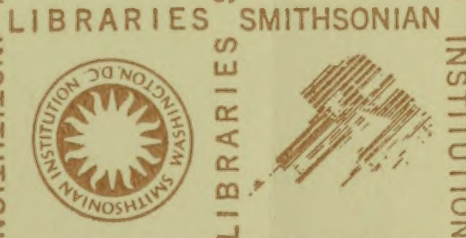

INST
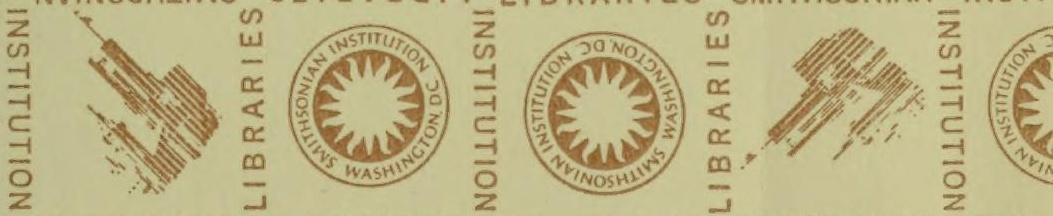

ES SMITHSONIAN
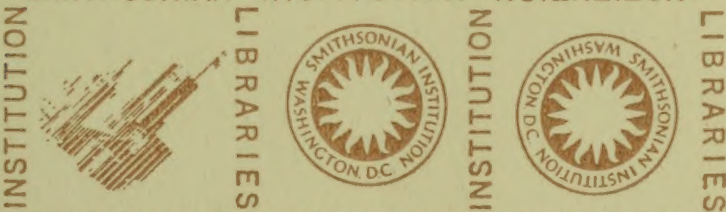

NHINOSHIIWS

$5 \exists I d$

SNI NHINOSHLIWS S $\exists I \forall \forall \forall 917$

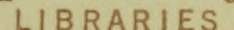

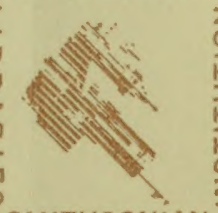

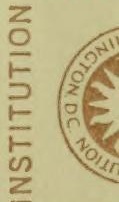

INST
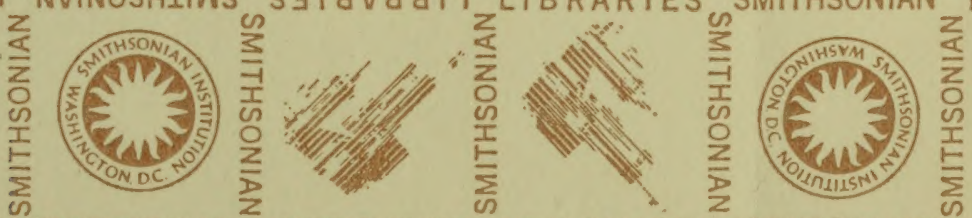

ES SMITHSONIAN

INSTITUTION

NOILOHLSNI

NHINOSHIIWS

S $\exists I d$

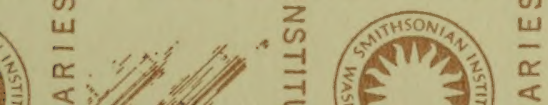

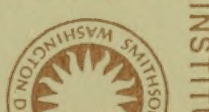

늘 




\section{EXTRAIT DES ANNALES DE LA SOCIÉTÉ ENTOMOLOGIQUE}

\section{DE FRANCE.}

( $2^{\mathrm{e}}$ Série, tome II. $1^{\mathrm{or}}$ trimestre 1814.)

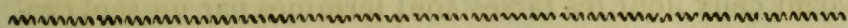

\section{IEEISION}

DE LA FAMille des Psélaphiens

Par M. le docteur CH. AUBÉ.

(Séance du 20 Décembre 1845.)

Lorsqu'en 1834 j'ai fait paraître ma Monographie des Psélaphiens, j'ai moins cédé ausentíment de mes propres forces qu'aux sollicitations de quelques entomologistes de mes amis, qūi m'ont poussé à ce travail presque contre ma volonté. Peu versé à celte époque dans l'étude des petites espèces, et surtout dans l'examen anatomique de leurs bouches, j'ai commis bon nombre d'erreurs que je vais chercher à réparer aujourd'hui. Parmi ces erreurs, les unes existent dans la classification et dans la nomenclature; les autres se retrouvent dans les dessins anatomiques, qui, il faut bien le reconnaître, sont d'une imperfection remarquable. Privé d'instrument à fort grossissement, j'ai dû disséquer et observer à l'aide d'une loupe ordinaire, moyen peu propre à laisser voir les choses telles qu'elles sont, lorsqu'on examine des organes appartenant à des animaux dont la longueur est souvent inférieure à un millimètre. Aussi ai-je cru voir quelquefois ce qui n'existait pas, tandis que je ne pouvais apercevoir ce 
qu'aujourd'hui je saisis à la première inspection, au moyen du microscope. L'erreur la plus grave que j'ai commise, est à coup sûr le classement du genre Batrisus, parmi ceux dont les tarses sont terminés par un seul crochet, tandis qu'il est bien évident qu'ils en ont deux. Cette erreur a été signalée pour la première fois par M. Erichson dans un excellent travail sur les Coléoptères de la Marche de Brandbourg (1). M. Erichson est du nombre des entomologistes qui acceptent rarement sur parole et veulent voir de leurs propres yeux. Pour mon propre compte, je le remercie bien sincèrement de m'avoir signalé une erreur que j'aurais bien certainement commise une seconde fois, tant j'avais de foi dans mon premier examen.

Dans la nomenclature il m'est souvent arrivé d'assigner des noms différents aux deux sexes d'une seule et même espèce; c'est surtout dans les genres Batrisus et Bythinus que j'ai failli. J'ai également à me reprocher de n'avoir pas toujours reconnu les espèces de Reichenbach et de les avoir quelquefois décrites sous des noms différents.

Passons maintenant aux erreurs anatomiques. Je dois d'abord signaler le défaut complet de mention d'un petit appendice membraneux qui se trouve ordinairement à l'extrémité du dernier article des palpes maxillaires, et que $M$. Erichson considère comme un véritable article, opinion que je ne puis partager. Selon M. Erichson, les palpes maxillaires de la plupart des Psélaphiens seraient composés de quatre articles, dont le premier serait le plus long et le dernier le plus petit, et constitué par ce petit appendice membraneux setiforme. Selon moi, al contraire, en admettant l'article de M. Ericlison comme va-

(1) Die Kafer der Mark Brandenburg. Berlin, 1857 . 
lable, ces mêmes palpes maxillaires seraient composés de cinq articles dont le second le plus long et le dernier le plus petit. M. Erichson ne considérant nos deux premiers articles que comme un seul et même, a cru en trouver un quatrième dans une petite pièce appendiculaire qui n'est réellement pas articulée et ne doit sa mobilité qu'à son organisation, qui est membranẹuse au lieu d'être cornée comme cela se présente généralemenı. Ge qui me rend antagoniste de l'opinion de M. Eríchson, c'est qu'en ne tenant aucun compte de ce petit appendice, je retrouve encore quatre articles aux palpes maxillaires, et qu'en outre, cet appendice est double dans les Claviger et les Chennium, et accompagne les trois derniers articles des palpes maxillaires des Ctinistes; mais ici, au lieu d'être simple comme dans les autres genres de Psélaphiens, il forme un petit faisceau de soies membraneuses. Je pense donc que les palpes maxillaires de la plupart des Psélaphiens sont quadriarticulés et que le dernier article, considéré comme tel par M. Erichson, n'est qu'un appendice membraneux dont il ne faut pas tenir compte.

Je ne parlage pas non plus l'opinion de M. Erichson sur le nombre des articles des palpes labiaux, qu'il croit être au nombre de trois. Cet entomologiste considère comme un article l'espèce de petite soie interne qu'offrent les palpes à leur extrémité. Ici l'erreur parait analogue à la première. Cette soie est ordinairement accompagnéo d'une autre entièrement semblable placée en dehors et -qui pourrait aussi bien qu'elle jouer le rôle d'article; et s'il fallait absolument trouver un véritable article dans l'un de ces deux appendices, je ne vois pas quelle raison en pourrail déterminer le choix.

En outre, cet appendice n'est pas toujours simple; il parait quelquefois bi-articulé dans les Batrisus, il est dou- 
ble dans les $\boldsymbol{T}$ ychus, bifide à son extrémité et accompagné à son côté externe d'une autre soie beaucoup plus petite dans le genre Metopias, et enfin unique dans les Claviger. Il faut donc considérer les palpes maxillaires comme étant ordinairement bi-articulés avec le dernier article muni de soies membraneuses variant de nombre et de forme.

Le travail que je publie aujourd'hui n'est, comme l'indique son nom, qu'une simple révision, dont le but principal est de rectifier les erreurs renfermées dans ma Monographie; aussi ne donnerai-je qu'une description synoptique des espèces déjà publiées et m'étendrai-je davantage sur les espèces nouvelles qui, depuis ma première publication, se sont accrues d'un nombre assez considérable.

\section{PSÉLAPHIENS.}

Mâchoires à divisions semi-cornées, ciliées en dedans, l'externe plus longue que l'interne.

Palpes màxillaires de un, deux ou quatre articles, généralement très-longs (1).

Menton tronqué, avec une languette semi-membraneuse, très-petite, peu apparente et se confondant souvent avec les paraglosses qui sont très grands et garnis de soies en dedans.

Palpes labiaux de un ou deux articles.

Mandibuies cornées, aiguës et dentées en dedans.

Antennes en massue ou moniliformes et rarement coudées.

(1) Dans plusieurs genres le premier article des palpes maxillaires est peu visible, court et s'articulant sans condyle et par simple rapprochement 
Elytres tronquées, ne recouvrant pas l'abdomen, ce dernier de cinq articles.

Pattes allongées; tarses de trois articles, terminés par un ou deux crochets.

Ces insectes sont carnassiers, à l'exception des Claviger, dont les mandibules courtes et larges dénotent un autre genre de vie.

\section{Tablenu synoptique ales Genres.}

$1^{\text {re }}$ SEctron. Antennes de onze articles.

$1^{\text {re }}$ Division. Tarses terminés par deux crochets.
A. Crochets inégaux.

Antennes coudées.

Antennes droites.
1. Metopias.

2. Batrisus.

B. Crochets égaux.

* Palpes maxillaires de trois arlicles. 3. Chenvium.

** Palpes maxillaires de quatre articles.

Les deux derniers articles ovoïdes.

4. Truus.

Le dernier article fusiforme.

5. Hayotus.

Le dernier article sécuriforme.

6. Phanisus.

Les trois derniers articles épineux en dehors. 7. Crenistes.

$2^{\mathrm{e}}$ DIvision. Tarses terminís par un seul crochet.

Dernier article des palpes maxillaires trèslong et en massue.

8. Psblapuús.

Dermier article des palpes maxillaires presque fusiforme à peine dilaté en dehors.

9. BRYAXIS.

Les deux derniers articles des palpes masillaires sécuriformes

10. Treuus. 
Le dernier article des palpes maxillaires sé. curiforme.

\section{Bxthinus.}

Corps allongé, cylindroïde; dernier article des palpes maxillaires légèrement dilatés en dedans; le dernier article des antennes très gros.

12. Trinium.

Corps allongé, déprimé; dernier article des palpes maxillaires conique.

13. Euplectus.

2e sEcrion. Antennes de six articles.

14. Claviger.

3e sEcrrow. Antennes de un article.

15. ARTicerus.

PREMIÈRE SEGTION.

Antennes de onze articles.

PREMIERE DIVISION.

Tarses terminés par deux crochets.

A. Crochets des tarses inégaux.

METOPIAS.

Gory. Mag. de Zool. de Guérin, cl, 9, pl. 42.

Marnax de Laporte. Etud. entom., p. 137.

Antenno geniculato, in tuberculo frontali inserta; palpi maxillares quadri-articulati, elongati, arliculo ultimo fusiforme, loviter inlus ampliato.

\section{Planch. vr. n. 1.}

Corps assez allongé et convexe. Tête triangulaire, ayant en avant, sur le front, un prolongement assez long sur lequel sont insérées les antennes; labre transversal à trois divisions, celle du milieu munie de deux petits appendi- 
ces membraneux; mandibules aiguës, ayant cinq à six dents; mâchoires à divisions presque égales en longueur et ciliées; palpes maxillaires de quatre articles : le premier très-petit, le second très long légèrement arqué et un peu en massue à son extrémité, le troisième presque cylindrique et allongé, le quatrième fusiforme légèrement dilaté en dedans et terminé par un très-petit appendice membraneux; menton coupé presque carrément; languette très-petite; palpes labiaux de deux articles : le premier très-petit, le second très-long et muni à son extrémité de trois soies membraneuses, l'une tout à fait en dehors, une seconde en dedans, bifide à son extrémité et accompagnée à son côté externe d'une troisième très-petite; paraglosses très-longs, arrondis à leur extrémité et garnis en dedans de soies très-espacées; antennes coudées: le premier article très-long et formant à lui seul plus du tiers de leur longueur. Corselel cordiforme. Elytres assez longues. Abdomen nullement rebordé. Pattes très-longues; tarses de trois articles: le premier très petit, les deux suivants presque égaux, et le dernier terminé par deux crochets inégaux.

\section{Metopias curculionoides.}

Gory. Magas. de Zool. de Guérin, cl. 9, pl. 42. Aubé. Monog. Pselaph., p. 13, tab. 78, fig. 1. Marnax curculionoides de Laporte, IIist. nat. des Anim., Artic., t. 1, p. 200.

Rufo-castaneus, dense velutinus: thorace cordalo, sulco medio impresso.

Long. 4 millim.

De Cayenne. Collection de MM. Gory et Reiche. 


\section{Batrisus.}

Aubé. Mronog. Pselaph., p. 45.

Pselaphus. Reich. Monog. Pselaph.

Bryaxis. Denny. Monog. Pselaph.

Antennce moliniformes in fossula lalerali inserta; palpi maxillares elongati, quadri-articulati, articulo ultimo fusiformi.

\section{Planch. vı, n. 2.}

Corps allongé et convexc. Tête globuleuse, ayant de chaque côté une fossette pour l'insertion des antennes; labre transversal largement échancré au milieu, oùil est muni de trois petits appendices membraneux; mandibules aiguës ayant cinq à six dents; mâchoires à divisions inégales, l'externe beaucoup plus longue, elles sont ciliées en dedans; palpes maxillaires de quatre articles: le premier très-petit, à peine perceptible (bien apparent dans le $B$. Delaporti), le second très-long, un peu renflé à son extrémité, le troisième petit, un peu triangulaire, le dernier fusiforme et terminé par un petit appendice membraneux; menton coupé presque carrément; languette très-petite; palpes labiaux de deux articles : le premier très-petit, le second très-long et muni à son extrémité de deux soies membraneuses, l'une externe et l'autre interne, cette dernière, sous un très-fort grossissement, paraît vaguement bi-articulée; paraglosses trèslongs, arrondis à leur extrémité et garnis en dedans de soies très-espacées; antennes moliniformes un peu renflées à leur extrémité. Corselet trapézoïdal, généralement marqués de sillons longitudinaux. Élytres très-convexes. Abdomen nullement rebordé. Pattes longues; cuisses renflées; tarses de trois articles: le premier très-petit, les deux suivants allongés et presque égaux, le dernier 
terminé par deux crochets inégaux; les antennes offrent dans les mâles une petite dent épineuse placée à la base et en dedans du dernier article.

Les Batrisus vivent en société avec différentes fourmis qui ne sont pas toujours les mêmes pour chaque espèce.

\section{Batrisus formicarius.}

Aubé. Monog. Pselaph., p. 46, tab. 89, fig. 1.

Lacordaire. Faune entomolog. des env. de Paris, p. 575.

Heer. Faun. Coleopt. Helvet., pars. 1, pag. 356.

Elongalus, cinnamomeus. Capile majusculo, reliculato, verticè tuberculalo, tuberculo magno in summo fossulato. Thorace trisulcalo.

\section{Long. 31 [ 2 mill.}

On le trouve probablement dans toute l'Europe tempérée. Il est assez rare aux environs de Paris, où on le rencontre sous les mousses au pied des vieux chênes, en société avec la Formica emarginata.

\section{Batrisus Germari.}

Elongatus, brunneo-castancus. Capile majusculo, leviusculo; verlicì tuberculato, luberculo levi, in summo fossulato. Thorace bisulcalo.

$$
\text { Long. } 34_{1} 2 \text { mill. }
$$

D'un châtain brun, assez luisant. Tête assez forte, presque lisse, ayant sur le vertex un tubercule assez élevé limité par deux sillons profonds qui viennent se réunir en avant; le tubercule est marqué sur son sommet d'une petite fossette allongée. Corselet marqué sur le côté d'un sillon profond qui vient se terminer en arrière dans une petite fossette réunie à unc autre petite fossette médiane par un petit sillon arqué en avant; nulle trace de sillon 2e Série, том. и. 
sur le milieu. Elytres un peu rougeâtres et marquées d'une strie suturale et d'une autre strie longitudinale qui, partant de la base, n'atteint pas tout à fait l'extrémité.

Il ressemble au formicarius dont il a la taille, mais il s'en distingue essentiellement par sa tête presque lisse et l'absence de sillon médian sur le corselel; il est aussi plus foncé en couleur.

Je n'ai vu que deux exemplaires de cette espèce; ils ont été pris au Brésil et m’ont été communiqués par M. le doct. Schaum à qui ils appartiennent.

\section{Batrisus Dregei.}

Elongalus, cinnamomeus. Capile majusculo, deplanalo; verticè vix tuberculato. Thorace ad basin fossula magna quadrangulare sulcoque medio anticè abbrevialo, impresso.

\section{Long. 31 , 2 mill.}

D'un brun clair, assez luisant. Tête large très-déprimée, à peine reticulée, ayant sur le vertex un tubercule à peine sailian!, lisse et entouré en avant et sur les côtés d'un large sillon demi-circulaire, venant aboutir de chaque côté à une fossette assez large et profonde. Corselet marqué en arrière d'une fosselte profonde quadrangulaire, dont l'angle antérieur s'allonge en un petit sillon sur le milieu du dos et est abregé en avan!; les angles latéraux de cette même fosselte forment également des petits sillons qui vont obliquement et en dehors ịsqu'au milieu du bord latéral du corselet. Elytres marquées d'une strie suturale et d'une autre strie longitudinale qui, partant de la base, atteint environ le milieu de leur longueur.

Il se distingue des deux précédents, surtout par la forme de la tête, qui est relativement plus large et considérablement déprimée, 
Je n'ai vu que deux indivilus de cette espèce renant tous deux du Cap, et appartenant l'un à M. Reiche et l'autre à M. Schaum.

\section{Batrisus albionicus.}

Aubé. Monog. Pselaph., p. 49, tab. 90, fig. 2.

Elongalus, nigro-piceus. Capile majusculo, leciusculo; verlicè luberculato, tuberculn levi, in summo fossula punctiformi impresso. Thorace bisulcato.

$$
\text { Long. } 21 \text { [2 mill. }
$$

Amérique du Nord. - Il fait aujourd'hui partie de la collection de M. Reiche.

\section{Batrisus riparius.}

Pselaphus riparius, Say. Journ. of the Acall. of Nat. Scienc. of Philadelph., tom. 1V, pirt. 1, p. 98.

Elongalus, cinnamomeus. Capile majusculo, ferè triangulari, reliculato; verlicè tuberculato, luberculo levi, lineola in summo impresso el fossulis obliquis anticè conjunctis circumducto. Thorace trisulcato.

$$
\text { Long. 21/2 mill. }
$$

Du Missouri. - J'ai vu un individu mâle de cette espèce; il appartient à $M$. Kunze, qui a eu l'obligeance de me le communiquer.

\section{Batrisus lineatocollis.}

Aubé. Monog. Pselaph.. pag. 60, 1ab. 90, fig. 3.

Elongalus, cinnamomeus. Capile majusculo, subliliter reliculalo, verticè tuberculato, tuberculo impresso; antennarum arliculo pe. uultimo maximo spherico. Thorace tri-sulcalo.

$$
\text { Long. } 2 \text { 1[2. mill. }
$$

Amérique du nord. - Il fait aujourd'hui partie de la collection de M. Reiche, qui ne possède qu'une femelle. 


\section{Batrisus Delaporti.}

Aubé. Monog. Pselaph., pag. 46, tab. 82, fig. 9.

Lacordaire. Faun. entom. des env. de Paris, p. 576.

Erichs. Kaefer der Mark Brand., tom. I, p. 265.

Elongalus, cinnamomeus, abdomine piceo. Capile reliculalo; verlicè tuberculato, tuberculo in summo fossulalo. Thorace tri-sulcato. Mraris antennarum articulo penullimo spherico majore, ùltimo fere aquali.

Long. 21 [ 2 mill..

Il se rencontre dans toute l'Europe tempérée et il est généralement assez rare, surtout le mâle, que je n'ai pas connu lors de la publication de ma monographie. Je l'ai pris a vec la Formica emarginata et la Myrmica rubra.

\section{Batrisus Schaumii.}

Elongatus, cinnamomeus. Capile reliculato,verlicè tuberculato, $t u$ berculo leviter elevato, fossula punctiformi vix impresso; antennis gracilioribus. Thorace trisulcalo. Elytris conspicue punclatis.

Long. 21/4 mill.

D'un brun clair, un peu luisant. Tête finement réticulée, ayant sur le vertex un tubercule peu saillant, marqué sur son sommet d'une petite impression ponctiforme, peu visible, et entouré de deux larges sillons un peu obliques, venant se réunir en avant à un autre sillon transversal. Antennes un peu plus longues que la tête ct le corselet réunis et assez grêles. Corselet marqué sur les côtés d'un sillon profond et sur le milieu d'un autre sillon moins senti; ces trois sillons venant aboutir en arrière à trois petites fossettes, réunies entre elles par une ligne enfoncée, transversale et bisinueuse. Elytras très visiblement ponctuées et marquées d'une strie suturale et d'une autre strie longitudinale, qui partant de la base n'alteint que le tiers environ de leur longueur. Il a quelque analogie avec le 
Delaporti, mais il est plus petit, unicolor. Ses antennes sont relativement plus grêles et plus aliongées et n'offrent pas dans le mâle un avant dernier article presque aussi fort que le dernier. Ses élytres sont aussi bien visiblement ponctuées.

Amérique du Nord. - Je n'ai vu qu'un seul individu mâle de cette espèce; il appartient à M. le docteur Schaum de IIalle, auquel la science est redevable d'un travail très-bien fait sur le genre Scydmæenus et qui m’a communiqué à moimême avec un désintéressement tout scientifique beaucoup de pièces et renseignements nécessaires à mon travail. Je lui ai dédié celle espèce comme un faible témoignage de ma reconnaissance.

\section{Batrisus venustus.}

Aubé. Monog. Pselaph., p. 48, tab. 90, fig. 1.

Lacord. Faum, entomol. des environs de Paris, p. 577.

Erichs. Keefer der Mark Brand., t. 1, p. 264.

Heer. Fann. Coleopt. Helvet., pars. 3, p. 2 כ̌.

Pselaphus venustus, Reich. Monog. Pselaph., p. 65, tabl. 2, fig. 18.

Bryaxis nigriventris, Denny.Monog. Pselaph., p. 41, tab. T, fig. 1.

Batrisus Brullei, Aubé. Monog. Pselaph, p. 47, tabl. 89, fig. 3.

Batrisus Buqueti, Aubé. Ilonog. Pselaph., p. 50, tabl. 90, fig. 4, mâle.

Elongalus, cinnamomeus, abdomine picco. Capile subliliter reliculalo; verlicè tuberculato, tuberculo vix elevalo, levi el in summo fossula punctiformi impresso. Thorace trisulcalo. Maris capitis lateribus majis elevatis.

Long. $21 \mid 2$ mill.

Il se trouve dans presque toute l'Europe, où il vit comme 
ses congénères en sociétć avec de petites fourmis sous les écorces ou dans les bois creux. M. Anjubault l'a pris au milieu de la Formica emarginata.

\section{Batrisus oculatus.}

Aubé. Monog. Pselaph., p. 48, tab. 89, fig. 4. Lacordaire. Faun, entomolog. des env. de Paris, p. 576.

Elongalus, cinnamomeus. Capile fere triangulari, subliliter reliculalo; verlicè tuberculato, tuberculo levi vix elevalo et in summo fossula impresso; lateribus elevatis, anticè prominentibus; oculis prominulis. Thorace trisulcalo. Tibiis posticis spinula armatis.

Long. 21 [ 2 mill.

Il se trouve en France, en Autriche et en Styrie. M. Anjubault l'a pris aux environs du Mans, dans une vieille souche de charme, également occupée par une petite société de la Myrnica rubra.

\section{Batrisus australis.}

Erichson, Archiv. fur naturgeschichte, tom. VII, p. 243.

oblongus, castaneus, fulvo-puoescens; verlicè carinalo. Thorace basi ulrinque dentalo, in medio impresso. Elytris pedibusque rufis.

$$
\text { Long. } 33 \text { [4 mill. (Erichson.) }
$$

\section{De la terre de Van-Diemen.(1).}

(1) N'ayant pas vu celte espèce, je crois devoir reproduire ici la description complète qu'en donne M. Erichson.

Balriso venuslo æqualis, castaneus, nitidus, fulvo pubescens. Antennæ capitis thoracisque longitudine, graciliores rubræ. Caput læve; fronte late subimpressa, basi utrinque foveolata; vertice leviter elevato et acute carinato. Thorax oblongus, subcylindricus, lateribus ante medium rotundato-dilatatis, subtiliter marginatis, 
12. Baitrisus? thoracicus (1).

Vict. Motsch. Mém. de la soc. des nat. de Mosc., tom. V, p. 415 , tabl. 16, lig. cC.

Caslaneus aut fuscus, subpubescens, oculis nigris; palpis arliculo ullimo valdè elongato, fusiformi, acuminato. Thorace plano suborbiculato uni-foveolato. Abdomine depressiusculo segmento primo valde dilatalo.

Long. 1 1/2 mill. (Vict. M.)

Pris par M. Vict. Motschoulsky, en Géorgie, dans un nid de la Formica capitata, Latreille.

\section{Batrisus? testaceus.}

Temnodera testacea, Hope.Trans. of the entom. societ. of Lond., tom. II, part. 1, p. 52, 1abl. 7, lig. 2.

Tolum corpus supra et infra rubro-testiccum. Thorace globoso superne inciso. Elytris ocatis, abruptè truncatis. Pedibus longissimis.

Long. 21 , 2 mili. (Hope.)

Je n'ai pas vu cette espèce que l'on rencontre dans le Succin)(2). Animé

basi medio fuveatus, fovea utrinque carinata dentis inslar elevala terminata. Elytra ampliora, late rufa, stria suturali integra, dorsali ante medium abbreviata. Abdomen apice altenuatum. Pedes rufi, tarsis testaceis. (Erichson).

(1) D'après la description el la figure que donne de cet insecte M. Victor Motschoulsky, je doute fort qu'il puisse faire parie du genre Balrisus.

(9) M. IIope a fail de celle espéce un lype de coupe générique matis il ussigne réllement aucuin caractere qui ne soil propue a la plupart des Pselaphiens, el d'apres la figure qu'il en donne je crois pouvoir le rapporter mais cependant avec doute à mon genre Batrisus. 


\section{B. Crochets des tarses égaux. \\ * Palpes maxillaires de trois àrticles.}

\section{Chennium.}

Latreille. Gen. Crust. et Insect., t. 3, p. 77.

Antenna moniliformes, in tuberculo frontali inserta. Palpi maxillares minus elongati, triarticulati; articuto ultimo ovoidali.

\section{Planch. III, n. 4.}

Corps allongé et un peu déprimé. Tête petite, ayant le front légèrement prolongé en avant en un petit tubercule sur lequel sont insérées les antennes; labre transversal, très-légèrement échancré au milieu; mandibules aigües, garnies dans leur moitié antérieure de dents très-petite et très-serrées; mâchoires courtes, robustes, à divisions inégales, l'externe un peu plus longue que l'interne et beaucoup plus forte; elles sont cilées en dedans; palpes maxilaires de trois articles: le premier très-petit, à peine visible, le second très fort et un peu en massue, le dernier presque ovoidal, coupé un peu obliquement à son extrémité et garni de deux petits appendices membraneux, l'un à son extrémité interne et l'autre tout à fait en dehors; menton cordiforme; languette très-petite, un peu échancrée à son sommet; palpes labiaux de deux articles, le premier très-petit, le second trois fois au moins aussi long et muni à son extrémité de deux soies membraneuses, l'une externe et l'autre interne, cette dernière un peu plus longue; paraglosses très-longs, un peu triangulaires et garnies en dedans de soies très espacées; antennes moniliformes. Corselet conique. Elytres déprimées. Abdomen légèrement déprimé et rebordé. Pattes assez longues; cuisses robustes; jambes renflées à leur extré- 
mité; tarses de trois articles, le premier très-petit, caché dans l'échancrure de la jambe, le second et troisième à peu près aussi long; ce dernier terminé par deux crochets égaux. Ge genre parait vivre avec les Fourmis.

\section{Chennium bituberculatum.}

Latreille. Gen. Grust. et Insect., t. 3, p. 77.

Aud-Serv. et Lep. de St-Farg., Enc. méth., t.10, p. 220. Aubé. Monog. Pselaph., p. 14, tabl. 78, fig. 2.

IIeer. Faum. Coleop. Helvet., pars. 1, p. 35 4.

Elongalus, depressiusculus, rufo-lestaceus, pube grisca velutinus. Capite antice altenuato, reticulato, in fronte cunaliculatc, utrinque luberculo aculo armato. Thorace ad basin fovcolato.

Long. 3 mill.

Cet insecte encore fort rare se trouve en France, en Allemagne, en ltalie, en Suisse et probablement sur presque tous les points de l'Europe. M. Anjubault, conservateur de la bibliothèque du Mans et entomologiste aussi zélé qu'éclairé en a pris deux exemplaires dont un m’a été généreusement sacrifié pour en examiner la bouche; il les a rencontrés en société avec la Myrmica cospilum

** Palpes maxillaires de quatre articles.

\section{Tyrus.}

Aubé.Monog. Pselaph., p. 15.

Erichson. Kaefer der Mark Brand., t. 1, p. 263.

Pselaphus. Panz. Faun. Germ., 89, f. 11.

Antenna moniliformes, apice clavate, in tuberculo frontali inserla. Palpi maxillares quadriarticulati, articulo ullimo ovalo.

$$
\text { Planch. III, n. } 3 .
$$

Corps allongé et très-médiocrement convexe. Tête ayant 
le front légèrement prolongé en avant en un petit tubercule sur lequel sont insérées les antennes; labre transversal, s'avançant au milieu en un angle très-mousse; mandibules aigues ayant quatre à cinq dents; mâchoires assez fortes, la division externe plus longue; elles sont garnies de cils très-longs; palpes maxillaires de quatre articles, le premier très-petit, le second assez long et un peu en massue, les deux autres presque égaux et ovoïdes, le dernier terminé par un appendice membraneux; menton coupé presque carrément; languette très-petite, échancrée au milieu; palpes labiaux de deux articles, le premier très-petit, le second très-fin, aussi long, et muni à son extrémité de deux soies membraneuses, l'une externe et l'autre interne, cette dernière plus courte; paraglosses très-longs et garnis en dedans de soies très-espacées; antennes moniliformes, un peu renflées à leur extrémité. Corselet ovoïde. Elytres un peu déprimées. Abdomen très-légèrement déprimé et rebordé. Pattes assez longues; cuisses très-légèrement renflées; tarses de trois articles, le premier très-petit, les deux autres assez longs, égaux entre eux, le dernier terminé par deux crochets égaux.

On ne connaît jusqu'à ce jour qu'une seule espèce de ce genre.

\section{Tyrus mucronatus.}

Aubé. Mlonog. Pselaph., p. 16, tabl. 78, fig. 3.

Erichson. Kiefer der Mark. Brand., t. 1, p. 263.

Pselaphus mucronatus. Panz. Faun. Germ., 89, fig. 11.

Gyl. Ins. Suec., 1. IV, p. 231.

Pselaphus insignis. Reich. Monog. Pselaph., p. 60, labl.2, fig. 16. 
Pselaphus sanguineus. Payk. Faun. Suec, t. III, p. 363.

Elongalus, piceus, antennis, elylris pedibusque rubris, verticè bipunctalo. Thorace fuccolis tribus linea arcuata connexis impresso. Trochanteribus quatuor primis spinula armatis.

IIIas. Trochanterum intermediorum spinula majore arcutala,

$$
\text { Long. } 21 \text { [2 mill. }
$$

Il se trouve en Allemagne et en Suède, sous la mousse, les écorces d'arbres et sous les pierres, où probablement il dévore de petiles larves et des Acariens.

\section{Hamotus (1).}

Antennno moniliformes, apice clavato, in fossula laterali frontis inserta. Palpi maxillares quadriarticulati, arliculo ultimo fusiformi.

Corps allongé et médiocrement convexe. Tête offrant de chaque côlé du front une petite cavité pour l'insertion des antennes, qui sont moniliformes et un peu renflées à leur extrémité ; palpes maxillaires assez longs, de quatre articles, le premier très-petit, le second très-allongé et en massue, le troisième très-petit et triangulaire, le dernier presque aussi long que le second, fusiforme et terminé à son extrémité par un petit appendice membraneux (2). Corselet ovoïde. Elytres un peu déprimées. Abdomen trèslégèrement déprimé et rebordé. Pattes assez longues; cuisses légèrement renflées; tarses de trois articles, le premier assez petit, le second deux fois aussi long environ que le précédent et terminé par deux crochets égaux.

(1) Nom sans aucune significalion.

(2) N'ayant pu faire la dissection de ce genre ni du suivanl, je me suis borné à donner les caractères extérieurs el perceptibles à l'aide d'une simple loupe. 
Ce genre ressemble beaucoup au Tyrus, dont il diffère par l'insertion de ses antennes et par les deux derniers articles de ses palpes maxillaires; il a aussi le facies des Bryaxis.

\section{Hamotus latericius.}

Elongatus, depressiusculus, rufo-castaneus, verlicè bipunctato. Thorace obcordato, foveolis tribus linea arcuata vix conspicua connexis impresso. Elytris in medio ad basin oblique breviler canaliculatis.

Mas. Trochanteribus intermediis spinula elongata armatis.

$$
\text { Long. } 2 \text { 2[3 mill. }
$$

Corps un peu allongé, un peu déprimé, d'un rouge châtin assez luisant. Tête lisse; marquée sur le côté de deux petites fossettes arrondies et tout à fait en avant, de deux p̉etits tubercules écartés; dernier article des antennes très-gros, aussi long que les trois précédents réunis et mousse à son extrémité. Corselet convexe, beaucoup plus rétréci en avant qu'en arrière où il est coupé carrément, et marqué à la base d'une petite fossette transversale et de deux autres arrondies, placées sur les côtés; ces trois fossettes réunies par une petite strie demi-circulaire à peine visible, et sur certains individus seulement. Elytres un peu élargies en arrière, marquée d'une strie longitudinale tout le long de la suture, et d'un petit sillon oblique, assez profond, placé au milieu de la base et atteignant le tiers environ de leur longueur. Abdomen très-lé. gèrement déprimé avec le premier segment à peine pllus long que le suivant. Pattes un peu plus claires.

De Colombie. - Je n'ai vu que trois individus de cette espèce, l'un dans la collection de M. Reiche, les autres m’ont été communiqués par MM. Schaum et Mærkel. 


\section{Hamotus bryaxoides.}

Elongalus,convexus, picco-ferrugineus antennis pedibusque ferrugineis; clylris sanguineis, verlicè bipunclato. Thorace ovalo, foveolis tribus impresso.

\section{Long. 2 mill.}

Corps allongé, convexe, d'un brun ferrugineux assez foncé. Tête lisse marquée entre les deux yeux de deux petites fossettes arrondies et tout à fait en avant de deux petits tubercules écartés; antennes ferrugineuses avec le dernier article très-gros, aussi long que les trois précédents réunis et mousse à son extrémité. Corselet ovoïde rétréci en avant et en arrière et marqué de trois impressions arrondies, l'une au milieu près de la base, et les deux autres sur les côtés. Elytres rouges à peine élargies en arrière, marquées d'une strie longitudinale tout le long de la suture, et d'une autre strie assez large et assez profonde, partant du milieu de la base et alteignant la moitié environ de leur longueur. Abdomen assez convexe, le premier segment à peine plus long que le suivant. Pattes ferrugineuses.

Il diflère du précédent par sa taille plus petite, sa forme plus cylindrique et plus parallèle, son corselet plus ovoïde et sa couleur générale.

De Colombie. - Je n'ai vu qu'un seul individu femelle de celte espèce; il appartient à H. Buquet.

\section{Hamotus humeralis.}

Elongatulus, convexiusculus, rufo-castaneus, abdomine nigro. Capile sublitissimè reticulato, vix bipunclala. Thorace ovato, foveolis tribus linea arcuala connexis impresso.

$$
\text { Long. } 12\rfloor 3 \text { mill. }
$$

Corps un peu allongé, assez convexe, d'un testacé rou- 
geâtre. Têle très finement reticulée, marquée entre les yeux de deux impressions arrondies à peine visibles et tout à fait en avant de deux petits tubercules allongés très rapprochés el séparés par un petil canal très-étroit. Antennes avec le dernier article assez gros, aussi long que les deux précédents réunis et mousse à son extrémité. Corșelet ovoïde, marqué à la base d'une petite fossette transversale et de deux autres arrondies, placées sur les côtés, ces trois fossettes réunies par une petite strie demicirculaire. Elytres à peine élargies en arrière, marquées d'une strie longitudinale tout le long de la suture, et d'une autre strie assez large et assez profonde, partant du milieu de la base et atteignant jusqu'à l'extrémité. Abdomen assez convexe et noir, le premier segment de la longueur du suivant. Pattes testacées.

Il diffère du précédent par sa taille plus petite, sa tête réticulée dont les deux tubercules antérieurs sont très rapprochés, et enfin par la couleur de son abdomen, qui est noire.

De la Caroline du nord. - Je n'ai vu qu'un individu femelle de cette espèce : il m'a été communiqué par M. le doct. Schaum de Halle.

\section{Phanisus (1).}

Antenno moniliformes, apice clavalo, in tuberculo frontali inserta. Palpi maxillares quadriarticulati, articulo ullimo securiformi. Elytris breviusculis.

Corps allongé et sensiblement déprimé. Tête ayant le front légèrement prolongé en avant en un petit tubercule sur lequel sont insérées les antennes, qui sont monilifor-

(1) Nom sans aucune signification. 
mes et un peu renflées à leur extrémité, le dernier article, de la longueur des deux précédents, est pyramidal; palpes maxillaires de quatre articles : le premier très-petit, le second allongé et en massue, le troisième très-petit et triangulaire, le quatrième de médiocre longueur sécuriforme et terminé par un petit appendice membraneux à peine visible. Corselet cordiforme. Elytres très-déprimées el très-courtes. Abdomen déprimé et largement rebordé. Pattes assez longues; cuisses très-légèrement renflées; tarses de trois articles: le premier très-petit, le second très-long, le troisième plus court de moitié que le précédent et terminé par deux crochets égaux (1).

\section{Phamisus Reichenbachii.}

Elongalus, depressiusculus, castaneo-cinnamomeus, pube teslacca dense vestitus. Thorace ad basin et latera profundè sulcalo.

\section{Long. 3 mill.}

Corps allongé et sensiblement déprimé, d'un châtain clair et entièrement recouvert d'un duvet fin et serré. Tête un peu retrécie en avant, a vec une fosselte assez large entre les yeux; cette fossette se prolonge en avant en un petit sillon qui divise le tubercule antennifere. Corselet cordiforme; les angles antérieurs très-arrondis, les postérieurs échancrés, le bord latéral terminé en arrière par une petite dent épineuse et relevée, le disque est marqué d'un sillon en fer à cheval qui occupe la base et les deux côtés. Elytres très-déprimées, courtes, tronquées un peu

(1) Cegenre a un facies tout particulier qui l'èloigne de tous les autres; il a il est vrai des palpes de Bythinus, mais ses pattes sont terminées par deux crochels.

Je n'ai vu qu'une seule espèce venant de la Colombie. 
obliquement en arrière; on n'observe d'autre strie que celle qui existe tout le long de la suture. Abdomen déprimé et très-largement rebordé. Pattes un peu plus pâles.

De Colombie. - Je n'ai vu qu'un seul exemplaire de cette espèce; il appartient à M. le marquis de La FertéSenectère.

\section{GTENISTES.}

Reich. Monog. Pselaph., p. 76.

Latreill. Reg. anim., t. 5, p. 165.

Aud. Serv. et Lep. de St-Farg. Ency. Meth., t. X, p. 220. Aubé. Monog. Pselaph., p. 17.

Heer. Faun. Coleopt. Helv., pars. 1, p. 354.

Dionyx, Aud. Serv. et Lep. de St-Farg. Ency. Meth. t. X, p. 220. (mas.)

Antennce elongatce, apice clavata, in tuberculo frontali inserta. Palpi maxillares quadri-arliculati, tribus arliculis ullimis apophysa setarum fasci terminata, externe instructis.

Planch. III, n. 5 .

Corps allongé et légèrement déprimé. Tête ayant le front légèrement prolongé en un petit tubercule sur lequel sont insérées les antennes; labre transversal coupé presque carrément, à peine arrondi ; mandibules aiguës, ayant quatre à cinq dents; mâchoires assez petites, Ia division externe beaucoup plus longue, elles sont ciliées en dedans; palpes maxillaires de quatre articles, dont les trois derniers sont armés en dehors d'une apophyse terminée par un petit faisceau de soies membraneuses qui, dans l'état de dessication, sont agglomérées; menton un peu échancré; languette petite se confondant avec les paraglosses qui sont très-grands et garnis en dedans de soies 
assez espacées; palpes labiaux de deux articles: le premier très-petit, le second trois fois environ aussi long et terminé par deux soies membraneuses, l'une externe et l'autre interne, cette dernière plus petite; antennes un peu renflées à leur extrémití. Corselet ovoïde ou cylindroconique. Elytres un peu déprimées. Abdomen rebordé. Pattes assez longues; cuisses légèrement renflées; tarses de trois articles, le premier très-petit, les deux autres assez longs, égaux entre eux, le dernier terminé par deux crochets égaux.

Ce genre habite les détritus de végétaux, les vieux fagots, et est assez répandu dans l'Europe méridionale, on en connait aussi une espèce de Colombie.

1. Ctenistes palpalis.

Reich.Monog. Pselaph., p. 76, tab. 1, f. A.

Latreil. Reg. anim., t. 5, p. 165.

Aud.-Serv. et Lep. de St-Farg., Ency. Meth., 10m. 10,

p. 220.

Aubé. Monog. Pselaph., pag. 17, tab. 79, fig. 1.

Heer. Faun. Coleopt. Helv., part. 1, p. 354.

Dionyx Dejeanii. Aud.-Serv. et Lep. de St-Farg. Ency.

Meth., t. X, p. 220 (mâle).

Aubé. Monng. Pselaph., pag. 18, tab. 79, fig. 2.

Elongalus, depressiusculus, lestaceus, pube albida sparsim teclus. capile inler oculos obsolete bipunclato. Thorace cylindrico conico, ad basin foveolato. Palporum maxillarum arliculo ullims anticè rotundato.

Mas. Antennarum articulis guatuor ultimis majoribus, Femina antennarum articulis tribus ultimis majoribus.

Long. 2 mill.

Cet insecte est répandu dans presque toute l'Europe, mais il préfère généralement les parties múridionales. $2^{\mathrm{e}}$ Série, T. 11. 
11. Cordier l'a cependant trouvé aux environs de Paris dans le courant de l'été 1843. Il se tient ordinairement sous les mousses, dans les détritus des végétaux et dans les vieux fagots.

\section{Ctenistes cequinoxialis.}

Elongalulus, depressiusculus, rufo-teslaceus; pube albida sparsim teclus. Capile in verlicè bituberculato. Thorace ovalo, ad basin foveolato. Palporum maxillarum articulo ultimo anticè àcule terminato.

\section{Long. $12[3$ mill.}

Corps un peu allongé et légèrement déprimé, d'un testacé rougeâtre et couvert de petits poils blancs très-épars. Tête un peu rétrécie en avant avec deux petits tubercules lisses sur le vertex et un petit bouquet de poils blancs en avant des yeux; le dernier article des palpes maxillaires terminé en pointe en avant. Corselet ovoïde, lisse en dessus, avec un petit faisceau de poils blancs aux angles postérieurs et une petite fossette vers la base, celte fossette également garnie de poils blanchâtres. Les élytres, l'abdomen et les paltes comme dans le palpalis.

Cette espèce est extrêmement voisine du palpalis; elle s'en distingue par sa taille un peu plus petite, ses antennes plus grêles, un corselet plus ovoïde et plus lisse en dessus, et enfin par le dernier article des palpes maxillaires qui, en outre de la petite apophyse épineuse latérale propre à ce genre, se termine encore en pointe en avant, tandis que dans le palpalis ce même article est arrondi.

De Colombie. - Je n'ai vu qu'un seul exemplaire de cette espèce, que je suppose être un mâle, parce que les quatre derniers articles des antennes sont plus forts que les autres; il appartient à M. le docteur Schaum de Halle, en Saxē. 


\section{Cienistes Ghilianii.}

Elongalus, depressiusculus, me-leslaceus, pube albida sparsim lectus. Capile reliculato, tri-foveolalo. Thorace fere spherico, ad basin fovcola impresso. Palporum maxillarum articulo ullimo antice acute terminato.

\section{Lonic. 21,2 mill.}

Corps allongé et légèrement déprimé, d'un testacé rou. geâtre, et couvert de petits poils blancs très-épars. Tête retrécie en avant, légèrement réticulée, marquée en dessus de trois petites fosseltes, deux en arrière et une autre en avant, et garnie en arrière des yeux d'un petit bouquet de poils blancs; le dernier article dis palpes maxillaires terminé en pointe en avant. Corselet presque sphérique, lisse en dessus, avec un petit faisceau de poils blancs aux angles postérieurs et une fussette très-petite vers la basse, cette fossette également garnie de poils blanchâtres; les élytres, l'abdomen et les pattes comme dans les palpalis; ces dernières un peu plus allongées.

Il diffère des palpalis par sa taille un peu plus grande, sa forme généralement plus parallèle; sun corselet presque globuleux, el aussi par le dernier article des palpes maxillaires qui, en outre de la petite apophyse épineuse latérale propre à ce genre, se termine encore en pointe en avant, tandis que dans le palpalis ce même article est arrondi.

Cet insecte a été pris par M. Ghiliani aux environs de Cadix, au nombre de trois exemplaires: l'un appartient à M. Reiche; le second, je crois, à M. Le marquis de La Ferté-Senectère, et le troisième fait partie de ma propre collection. Les deux seuls exemplaires que j'ai examinés sont probablement des femelles; les trois derniers articles des antennes seuls sont plus forts que les autres. 
4. Clenistes? carinatus.

- Say. Journ. of the Acad. of Nat. scienc. of Philadelph., 1. IV, part. 1, p. 97.

Elongalus, depressiusculus, rufo-ferrugineus, elylris pallidioribus, pube brevi sparsim tectus. Capite tri-foveolato. Thorace punctato, Elytris punctatis, bicarinatis. Abdomine tri-carinato.

$$
\text { Long. } 21 \text { [ } 4 \text { mill. (Say.) }
$$

Des Etats-Unis d'Amérique, où, d'après Say, il n'est pas rare sous les écorces du Pin jaune.

Je n'ai vu que deux individus de cette espèce, mais privés de leur tête, aussi ne l'ai-je rapportée au genre Ctenistes qu'avec doute et d'après les indications de Say, qui croil devoir le rapporter lui-même à ce genre.

\section{Deuxième Division.}

Tarses terminés par un seul crochet.

\section{PSELAPHUS.}

Herbst. Kaef., IV, p. 109.

Antennce moniliformes, apice clavata, in tuberculo frontali inserta. Palpi maxillares longissimi, quadri-arliculati, articulo ultimo valde elongato, claviformi.

$$
\text { Planch. III, n. } 6 .
$$

Corps allongé et un peu déprimé. Tête ayant le front légèrement prolongé en avant en un petit tubercule sur lequel sont insérées les antennes; labre transversal et largement arrondi; mandibules aiguës, avec trois ou quatre dents; mâchoires à divisions inégales, l'externe un peu plus longue : elles sont ciliées en dedans; palpes maxillaires de quatre articles : le premier assez long, filiforme et un peu arqué, le second un peu plus long et légèrement renflé à son extrémité, le troisième très-petit et triangu- 
laire, le quatrième aussi long à peu près que les trois autres réunis, en massue et terminé par un petit appendice membraneux; menton coupé presque carrément; la!ıguelte très-petite confondue avec les paraglosses qui sont très-grands et garnis en dedans de six à huit soies mem. braneuses; palpes labiaux de deux articles: le premier très-petit, le second plus large et terminé par deux soies, l'une externe et l'autre interne, cette dernière un peu plus petite; antennes moniliformes, un peu renflées à l'extrémité. Corselet ovoïde. Elytres un peu déprimées. Abdomen rebordé, le premier segment très-grand. Pattes assez longues, les cuisses légèrement renflées ; les tarses de trois articles: le premier très-petil, le second trèslong, le dernier un peu plus court que le précédent et terminé par un seul corselet.

Ces insectes vivent dans les prés, aux pieds des arbres ou des roseaux, retraite dont ils sortent le soir pour la chasse.

\section{Pselaphus Heisei.}

Herbst. Kaef., t. IV, p.109, tabl. 36, f. 9, 10.

Reich. Monog. Pselaph., p. 28, t. 1, f. 2.

Leach. Zool. Misc., 1. 3, p. 87.

Denny. Monog. Pselaph., p. 45, tabl. 6, f. 2.

Latreil. Gen. Grust. et Insect., t. 3, p. 76.

Gyl. Ins. Suec., t. 4, p. 223.

Aubé. Monog. Pselaph., p. 19, tabl. 80, f. 1.

Lacord. Fawn. Entom. des env. de Paris, p. 561.

Erichs. Kol. des Mark. Brand., 1. 1, p. 266.

P'selaphus Hersbtii. Reich. Monog. Pselaph., p. 25; tab.1, fig. 1.

Leach. Zool. Misc., t. 3. p. 87. 
Denny. Monog. Pselaph., p. 43, tabl. 39, fig. 10. Aubé. Monog. Pselaph., p. 20, tabl. 80, fig. 2.

Elongatus, depressiusculus, castaneo-rufus. Thorace elongato ovali.

$$
\text { Long. } 2 \text { mill. }
$$

Il varie du roux au brun de poix.

On le rencontre assez fréquemment dans les marais, au pied des arbres et des grandes herbes.

2. Pselaphus acuminatus.

Vict. Mostch. Mém. de la soc.des Nal. de Mosk., t. IV, p. 314, tab. 11, fig, a A.

Elongalus, rufus, nilidus, posticè dilatalus. Capite tri-foveolato; elytris dilulioribus; segmento primo pone elytris maximo, utrinque incrassalo, secundo mullo minore, terlio in medio nodulo compresso obtuso produclo.

In masculis segmento tertio cum reliquis planis.

$$
\text { Long. 3[4 lig. - Larg. 1/4 lig. (Vict. M.) }
$$

Pris par M. V. Motschoulsky, sous les pierres dans les steppes d'Elisabethpol, en Géorgie méridionale.

\section{Pselaph. dresdensis.}

Herbst. Kaf., t. IV, p. 110, tabl. 39, fig. 11.

Reich. Monog. Pselaph., p. 32, tabl. 1, fig. 4.

Leach. Zool. Misc., t. 3, p. 87.

Denny. Monog. Pselaph., p. 47, t. 10, fig. 2.

Gyl. Ins, \$uec., t. 4, p. 225.

Aubé. Monog. Pselaph., p. 22, tabl. 80, fig. 4.

Lacord. Faun. Entomol. des env. de Paris, p. 562.

Erischs. Kaf. des Mark. Brand., t. 1, p. 267.

Heer. Faun. Coleop. Helv., part. 1, p. 356. 
Anthicus dresdensis. Payk Faun. Suec., t. 3, p. 364.

Pselaphus longicollis. Reich. Monog. Pselaph., pag. 30, tabl. 1, fig. 3.

Leach. Zool, Misc., t. 3, p. 17.

Denny. Monog. Pselaph., p. 46, tabl. 10, fig.

Gyl. Ins. Suec., t. 4., p. 224.

Aubé. Monog. Pselaph., p. 21, tabl. 80, fig. 3.

Lacord. Faun. Entomol. des cnv. de Paris, p. 562.

Elongatus, depressiusculus, castanco-brunneus, clytris pedibusque dilutioribus. Thorace suborali, ad basin sulco semi-circulari impresso.

Long. 2 mill.

Il se trouve dans toute l'Europe, au pied des herbes, dans les marais, mais il n'est commun nulle part (1).

\section{Bryaxis.}

Leach. Zool. Misc., t. 3, p. 85.

Pselaphus. Reich. Monog. Pselaph., p. 17.

Anthicus. Fab. Syst. Eleut., t. 1.

Anlennee aut moniliformes aul ex articulis, plus minus ve numerosis angulatis composite, apice clavate, in fossula laterali inserta. Palpi maxillares elongatuli, arliculo ullimo fusiformi.

Planch. III, n. 7 .

Corps peu allongé et convexe. Tête offrant de chaque côté du front une petite cavité pour l'insertion des an-

(1) M. Erichson Kafer der Mark Brand.p. 367, à l'article Pselpahus, parle d'une autre espèce de ce genre qui diffère du Iteisei par le filet du dernier article des palpes maxillaires qui est plus long que la massue. Comme M. Erichson n'a pas publié la description de cet insecte, je suis obligé de le passer sous silence ne l'ayant pas eu mol-même à ma disposition. 
tennes; labre transversal coupé presque carrément et muni au milieu de deux petits appendices membraneux; mandibules aigues a vec trois ou quatre dents; mâchoires à divisions inégales, l'externe plus grande el plus longue; elles sont ciliées en dedans; palpes maxilliaires de quatre articles : le premier très-petit, le second assez long et claviforme, le troisième petit, presque globuleux et anguleux en dedans, le dernier fusiforme et terminé par un petit appendice membraneux; menton coupé presque carrément; languette très-petite se confondant avec les paraglosses qui sont assez grands, un peu moins longs que les palpes et garnis en dedans de soies rares et écartées; palpes labiaux de deux articles : le premier très petit, le second trois fois environ aussi long et terminé par deux soies membraneuses à peu près de même longueur; antennes souvent moniliformes, ayant quelquefois aussi quelques articles anguleux; elles sont un peu renflées à leur extrémité. Corselet généralement cordiforme et marqué de trois fosseltes arrondies. Elytres convexes. Abdomen rebordé, le premier segment ordinairement très-grand. Pattes longues; cuisses un peu renflées; tarses de trois articles: le premier très-petit, les deux autres très-longs, presque égaux, le dernier terminé par un seul crochet.

Ces insectes ont le même genre de vie que les Pselaphus.

\section{Trois fossettes sur le corselet.}

A. Fossettes de corselet à peu près égales.

a. Fossettes réunies par un sillon transversal.

1. Bryaxis sanguinea (1).

Leach. Zool. Misc., t. 3, p. 85 (femelle).

(1) Malgré l'assertion de M, Motschoulsky qui prétend avoir sou, 
Denny. Monog. Pselaph., p. 34, tabl.7, figure 3 (femelle). Aubé. Monog Pselaph., p. 25, tabl. 81, fig. 2 (femelle). Lacord. Faun. Entomol. des env. de Paris, p. 564 (femelle).

Erichs. Kref. der Mark. Brand., t. 1, p. 268 (mâle et femelle).

Heer. Faun. Coleopt. Helvet., pars., p. 1, 357 (femelle). Pselaphus sanguinues. Ill. Kcef. Preus., 291 (femelle).

Reich. Monog. Pselaph., p. 49, tabl. 2, fig. 11 (femelle). Anthicus sanguineus. Fab. Syst. Eleut., t. 1, p. 293 (femelle).

Bryaxis longiconis. Leach. Zool. Misc., 1. 3, p. 85 (mâle). Denny. Monog. Pseluph., p. 32, tabl. 7, fig. 2 (mâle).

Aubé. Monog. Pselaph., p. 24, t. 81, fig. 1 (mâle).

Lacord. Faun. Entomol. des env. de Paris., p. 563 (mâle). Bryaxis laminata. Vict. Mostch. Mag. Zool. de Guer., cl. 9,pl. 171 (mâle variété).

Nigro-picea, nilida; antennis pedibusque ferrugineo-piceis; clytris ferrugineis.

Mas. Antennis longioribus; pectore abdomineque subtus fossulatis; in non nullis pectore lamina instructo.

$$
\text { Long. } 12 \text { 3 mill. }
$$

Il est très-commun dans les marais.

ven et son B. laminata, j'ai la certitude que M. Motschoulsky a cru voir ce qui n'étail qu'un simulacre; car je me suis assurè par la dissection que le $B$. sanguinea est réellement une femelle, tandis que les $B$. longicornis et laminata sont des mâles. Maintenant comment expliquer la présence de celle petile lame stenale qu'on observe chez le second, tandis qu'elle manque chez le premier. Ne pourrait elle pas être caduque el n'exister que jusqu'après l'accouplement. C'est encore un mystère à pénétrer. 
b. Fossettes du corselet libres.

* Abdomen semblable dans les deux sexes.

2. Bryaxis fossulata.

Leach. Zool. MI isc., t. 3, p. 86.

Denny. Monog. Pselaph., p. 37, tabl. 8, fig. 1.

Aubé. Monog. Pselaph., p. 25, tabl. 81; fig. 3.

Lacord. Faun. Entomol. des env. de Paris, p. 564.

Erichs. Kaf der Mark. Brand., t. 1, p. 270.

Heer. Faun. Coleop. Helvet., part. 1, p. 357.

Pselaphus fossulatus. Reich. Monog. Pselaph., pag. 54, tabl. 2, fig. 13.

Gyl. Ins. Suec., t. 4, p. 233.

Piceo-castanea; antennis pedibusque rufo-testaceis. Mas. Trochanteribus anterioribus oblusè denticulatis.

Long. 1 millim. 112.

Très-commun dans les marais.

Cette espèce, sans être réellement aptère, ne doit pas pouvoir voler; ses ailes sont très-courtes et très-étroites et n'offrent environ que le huitième de la surface que présentent celles d'une espèce plus petite, le $\boldsymbol{B}$. impressa.

\section{Bryaxis tibialis.}

Nigro-picea, nitida; antennis et pedibus ferrugineo-piceis; elytris sanguineis.

Mas. Tibiis anterioribus emarginatis trochanteribusque prioribus acute denticulatis.

$$
\text { Long. } 21 / 4 \text { mill. }
$$

Corps un peu allongé, d'un noir de poix assez brillant. 
Tèle marquée de trois impressions arrondies, assez enfoncées, deux sur le vertex et une autre un peu plus grande tout à fait en avant; antennes un peu ferrugineuses. Corselet fortement rétréci en avant et en arrière, dilaté au milieu et marqué de trois fossettes; l'une au milieu près de la base, un peu oblongue, et une autre arrondie, placée de chaque côté et sur le disque. Elytres d'un beau rouge, un peu rembrunies à la base et à l'extrémité, marquées d'une strie suturale et d'une autre partant du milieu de la base et n'atteignant pas tout à fait l'extrémité. Abdomen marqué à sa base de deux petites stries un peu obliques, à peine senties; le premier segment beaucoup plus long que les suivants. Pattes ferrugineuses; les tibias antérieurs des mâles largement échancré en dedans, l'échancrure armée à ses deux extrémités de deux dents très-petites.

Cet insecte a été rapporté de Sardaigne par M. le professeur Géné, de Turin.

\section{Bryaxis xanthoptera.}

Pselaphus xanthoptera. Reich. Monog. Pselaph., p. 56, tabl, 2, fig: 14.

Bryaxis rubripennis. Aubé. Monog. Pselaph., pag. 29, tabl. 83, fig. 2 (mâle.)

Lacord. Faun. Entomol, des env. de Paris, p. 566.

Bryaxis depressa (1). Aubé. Monog. Pselaph., pag. 28, tabl. 82, fig. 3 (femelle.)

Bryaxis assimilis. Curtis. British. Entom., t. 7, n. 315?

(1) J'ai décrit dans ma monographle sous le nom de $B$. depressa, un individu femelle de celle espèce, Jeune encore et mal dévelonpé, le seul que j'ai pu me procurer à l'époque de celte publlcalion. 
Nigro-picea, nitidula; antennis et pedibus ferrugineo-piceis; elytris sanguineis. Thorace subtilissime reliculato, rossula ad basin in disco aliis que duabus in laleribus ipsis impresso.

Mas. Trochanteribus anterioribus acute denticulatis tibiisque intermediis et posticis apice apophysa minima instructis.

Long. 2 mill.

Il se trouve en France, en Autriche, en Styrie et en Saxe.

5. Bryaxis hemoptera.

Bryaxis xanthoptera. Aubé. Monog. Pselaph., pag. 29, tabl. 83, fig. 3.

Bryaxis spinicoxis. Vict. Motsch. Mém. de la Soc. des Nat. de Mosk., t. IV, p. 317, tabl. XI, fig. B. d.?

Nigro-picea, nitida; antennis et pedibus feurugineo-piceis; elytris sanguineo-brunneis. Thorace in disco ipso tri-foveolato.

Mas. Trochanteribus anterioribus acule denticulatis, tibiisque intermediis el posticis apice apophysa minima instructis.

\section{Long. $13[4$ mill.}

Il se trouve dans toute l'Europe dans les prés humides; mais il est généralement rare partout.

\section{Bryaxis Lefebvrii.}

Aubé. Monog. Pselaph., p. 28, tabl. 83, fig. 1.

Lacord. Faun. Entomol. des env. de Paris, p. 566.

Heer. Faun. Coleopt. Helvet., pars. 1, p. 358.

Nigro-picea, nilida; antennis el pedibus ferrugineo-piceis, elytris sanguineo-brunneis. Thorace posticè coarclato in disco ipso trifoveolato. 
Mas. Trochanteribus anterioribus acule spinosis; tibiisque inlermemediis et posticis apophysa tenuissima vix instructis.

Long. 11 [4 mill.

Très-commun dans les prés humides.

** Abdomen différent dans les deux sexes.

7. Bryaxis Helferi.

Schmidt. De Pselaph. Faun. Pragen. (Dissertat. inaug.), p. 33.

Bryaxis pulchella. Schaum, Zietsch. fur die Entom. : von. Germ., t. 4, p. 192.

Nigro-picea, nilida; antennis pedibusque ferrugineis; elylris sanguineis.

Mas. Trochanteribus anterioribus acute spinosis. Abdomine segmento primo apice fossula semiarculari impresso, fossula margine antico in tuberculo elevalo.

Long. $11[4$ mill.

Les femelles de cette espèce ont la plus grande analogie avec celle du $B$. Lefebvrii avec lesquelles il est trèsfacile de les confondre; elles sont cependant généralement un peu plus trapues et ont le corselet un peu plus court et moins rétréci en arrière.

Il se rencontre sur le bord des lacs salés qu'il parait fréquenter exclusivement; il a été pris en très-grande abondance en Sicile par MM. Helfer et Ghiliani et en Saxe par M. Schaum. 


\section{Bryaxis Schuppelii.}

Nigro-picea, nilida; antennis pedibusque ferrugineis; elytris sanguineis.

Mas. Trochanteribus anterioribus obluse denticulatis; abdominis segmento primo posticè in medio elcvato, secundo anticè excavato.

$$
\text { Long. } 11 \text { [ } 4 \text { mill. }
$$

Corps peu allongé, d'un noir de poix assez luisant. Tête marquée de trois impressions arrondies, assez enfoncées, deux sur le vertex et une autre un peu plus grande tout à fait en avant; antennes ferrugineuses. Corselet fortement rétréci en avant el en arrière, dilaté un peu avañt le milieu et marqué de trois fossettes ariondies, l'une au milieu près de la base et une autre de chaque côté et sur le disque. Elytres d'un brun-rouge un peu rembruni à la base et à l'extrémité, marquées d'une strie suturale et d'une autre partant du milieu de la base et n'atteignant pas tout à fait l'extrémité. Abdomen marqué à la base de deux petites stries un peu obliques et à peine senties; le premier segment beaucoup plus longs que les suivants, relevé en pètite voute tout à fait à son extrémité et au milieu, le second marqué en avant d'une petite fossette quadrangulaire qui s'enfonce sous la petite voute que présente le premier. Pattes ferrugineuses; les trochanters antérieurs très-légèrement saillants. Je n'ai vu que cinq individus mâles de cette espèce tous pris aux environs de Trieste.

Il répond, je crois, au $B$. foveola dont parle M. Motschoulski dans le Bulletin pour 1840 de la Société des Naturalistes de Moskou; mais dont il n'a donné la des. cription nulle part.

9. Bryaxis homatica:

Leach. Zool. Misc, t. 3, p. 86. 
Denny. Monog. Pselaph., p. 38, labl. 8, fig. 2.

Aubé. Monog. Pselaph., p. 26, pl. 82, fig. 1.

Lacord. Faun. Entomol. des env. de Paris, p. 565.

Erichs. Kref. der Mark. Brand., t. I, p. 269.

Heer. Faun. Coleopt. Helvct., pars. 1, p. 358.

Pselaph. hocmaticus. Reich. Mlonog. Pselaph, pag. 52, tabl. 2, fig. 12.

Bryaxis nodosa. Vict. Motch. Mém. de lu Société des Nat. de Mosk., t. 4, p. 315, tabl. IX, fig. B. b.

Rubro-cinnamomeus; antennis pedibusque dilatioribus. Abdominis segmento primo coleris mullo majore, depressiusculo, in maribus, posticì bisinuato, tum utrinque fovcolato, tum infoveolato aut bidenticulalo cum secundo segmento tuberculato.

\section{Long. 11 [2 mill.}

Je me suis assuré que le $B$. nodosa de M. Vict. Molschoulsky n'e:t encore qu'une forme du mâle de cette espèce; j'ai pu vérifier ce fait sur un exemplaire envoyé à M. Guérin par M. Motschoulsky lui-même. Il est à noter que M. Motschoulsky, dans, son mémoire considère le type du $B$. nodosa comme une femelle, tandis qu'il doit être regardé comme un mâle. J'ai acquis la certitude par la dissection que tout les Bryaxis hematica, dont le premier segment de l'abdomen n'est pas coupé carrément en arrière sont des mâles. N'a-t-on pas lieu dé s'étonner des formes si variées qu'affecte l'adomen de cet insecte?

Ce Bryaxis est extrêment commun dans toute l'Europe, on le rencontre dans les prés humides. M. Reiche possède dans sa collection un exemplaire de la variété mâle dont l'abdomen offre de chaque côté une petite fossette profonde qui vient des Etats-Unis d'Amérique et que $\mathbb{M}$. le comte Dejean avait séparé sous le nom de $B$. obscura. 
10. Bryaxis dentata.

Pselaphus dentatus. Say. Journ. of the Acad. of Nat. scienć. of Philadelph., t. IV, pars. 1, p. 99 (femelle).

Bryaxis abdominalis. Aubé. Monog. Pselaph., pag. 27, tabl. 82, fig. 2 (mâle).

Rubro-cinnamomeus; antennis pedibusque dilutioribus. Abdominis segmento primo cateris paulo majore, convexiusculo, in maribus suprà biluberculalo, apice profunde emarginalo, secundo late excavato, apice bifido.

Long. 11 [2 mill.

Des Etats-Unis. - Cette espèce ressemble beaucoup à l'hoematica; mais est généralement un peu plus convexe surtout sur les élytres et sur l'abdomen; le premier segment de ce dernier est aussi beaucoup moins large. Je n'ai vu qu'un seul mâle, peut-être offre-t-il comme son congénère une grande variété dans les formes de son abdomen.

\section{Bryaxis furcata.}

Vict. Mostch. Mém. de la Soc. des Nat. de Mosk., t. 4, p. 316, tabl. XI, fig. C. c.

Nigro-picea ; elylris piceo-ferrugineis. Thorace subgloboso.

Mas. Abdominis segmento primo apice late emarginato, secundo profundè excavalo et apice apophysis duabus acutis furcato.

M. Motschoulsky a pris ce Bryaxis à Tiflis, en Géorgie russe. J'en ai vu une paire, mâle et femelle, rapportée des environs d'Alger par M. Lucas. 
B. Fóssettes du corselet inégales.

a. Antemnes régulièrement claviformes.

* Corselet visiblement ponctué.

12. Bryaxis juncorum.

Leach. Zool. Misc., t. III, p. 86.

Denny. Monog. Pselaph., p. 40, tab. 8, fig. 3

Aubé. Monog. Pselaph., p. 32, tab. 84, iig. 5 .

Lacord. Faun. entomol. des env. de Pais, p. 563.

Erichs, Kaf. der Mark Brand., t. I, p. 274.

Heer. Faun. Coleopt. Ilclvet., pars. 1, 358.

Reichenbachia juncorum. Leach.Zool. Joum., t. II, p. 452.

lubro-cinnamomea, untennis pedibusque dilutioribus.

Mas. Pectore et abdomine subtus late foveolatis.

Long. 11 [4 mill.

Assez commun le soir sur les herbes dans les bois hulmides.

** Corselet n'étant pas très-visiblemerit ponctué.

13. Bryaxis tomentosa.

Aubé. Mronog. Pselaph., p. 33, tab. 81, tig. 4.

Iufo-cimmamomea, valdì pubescens. Thorace in medio forenlu vix conspicua el utrinque depressione obsoletissima impresso.

$$
\text { Long. } 111^{4} \text { mill. }
$$

Be l'Amérique du Nord (Etals-1 nis), -. Jai vu cutatr 2e Serie, том. 11. 
individus de cette espèce qui mont paru appartenir au même sexe; je crois que ce sont des femelles.

Collection de M. Reiche.

\section{Bryaxis Chevrieri.}

Rufo-cinnamomea, nitidula, antennis pedibusque dilutioribus, abdomen infuscato. Thoracis fossula intermedia lenuissima, laleralibus mullo majoribus.

Long. $11_{[} 3$ mill.

Corps à peine allongé, d'un testacé un peu rougeâtre et assez luisant. Tête marquée de trois impressions arrondies, deux sur le vertex et une autre un peu plus grande tout à fait en avant. Antennes testacées. Corselet rétréci en avant et en arrière, dilaté un peu avant le milieu, très finement ponctué, ce qui n'est visible qu'à l'aide d'un fort grossissement, et marqué de trois fossettes: une infiniment petite au milieu, près de la base, une autre beaucoup plus grande de chaque côté et sur le disque. Elytres assez convexes, marquées d'une strie suturale et d'une autre partant du milieu de la base et n'atteignant pas tout à fait l'extrémité. Abdomen légèrement rembruni, assez convexe et marqué à sa base de deux petites stries un peu obliques et à peine senties; le premier segment est environ deux fois plus long que le suivant. Pattes testacées.

Il ressemble beaucoup au $\mathrm{Br}$. juncorum dont il diffère surtout par le corselet qui n'est pas aussi visiblement ponctué, dont la ponctuation est beaucoup moins serrée et ne le fait pas paraitte terne.

J'ai ru cinq individus de celte espèce : deux appartenanı à M. Chevrier, de Genève, deux à M. Kunze et le 
dernier m’ayant été communiqué par M. Schaum. Les quatre premiers ont été pris en Italie et le dernier en Syrie. Tous m'ont paru apparınir au même sexe; je crois que ce sont des femelles.

\section{Bryaxis rubra.}

Rubro-cinnamomea, nilidula, cntennis pedibusque dilutioribus. Thorace subgloboso, fossula intermedia minima, lateralibus paulò majoribus.

\section{Long. 11 14 mill.}

Corps à peine allongé, d'un rouge testacè et luisant. Tête marquée de trois impressions arrondies, deux sur le vertex et une autre un peu plus grande tout à fait en avant. Antennes testacées. Corselet presque globuleux, lisse, ayant trois fossettes: l'une très-petile au milieu, près de la base, et une autre de chaque côté un peu plus grande, placée tout à fait en dehors el presque sur le flanc luimême. Elytres assez convexes, marquées d'une stric suturale et d'une autre partant du milieu de la base et n'atteignant que le milieu environ. Abdomen assez convexe, le premier segment deux fois aussi long que le second et marque à sa base de deux petites stries obliques à peine senties. Pattes testacées.

De Colombie. - J'ai vu deux individus de cette espèce appartenant, l'un à M. Reiche et l'autre à M. le docteur Schaum. lls m'ont paru appartenir au même sexe et je crois que ce sont des femelles.

16. Bryaxis opuntice.

Schmidt. De Pselaph. Faun. Prag., p. 31 .

Picen, antemnis pedibusque teslareis, elyhis sanguineis. Thoracis fos- 
sula incrmedia tonuissima, lateralibus multo majoribus. Antennis longiusculis gracilibus.

Mas. Tibiis intermediis spinula minima intus ad apiccm instructis.

Il se trouve dans l'Europe méridionale et dan's le nord de l'Afrique. J'en possède deux individus pris en Espagne et un autre en Algérie.

\section{Bryaxis rubricunda.}

Picea, antennis pedibusque leslaceis, elytris sanguineis. Thoracis fos sula intermedia minima, lateralibus nutto majoribus. Antennis breviusculis.

Mas. Tibiis intermediis spinula minima intus ad apicem instructis.

\section{Long. 11,2 mill.}

Corps peu allongé, d'un brun de poix assez foncé. Tête marquée de trois impressions arrondies, deux sur le vertes ct une autre un peu plus grande tout à fait en avant. Antennes testacées. Corsclet rútréci en avant el en arrière, dilaté environ au milieu, ayant trois fossettes : l'une nssez pelite au milieu, près de la base, une autre de chaque côté beaucoup plus grande et sur le disque. Elytres roligeâtres à peine rembrunies à la base ei à l'exirémité, assez convexes, marquées d'une strie sulurale et d'une autre parlant du milieu de la base et nalteignant pas l'extrémité. Abdomen assez convexe, le premier seģment une fois aussi long que le suivant el mirqué à la base de leux petites stries à peine senties. Pattes testacécs.

Il a la plus grande analogio avec le Br. opuntice, dont il ne diffère récllement que par la fossette intermédiaire du corselet qui est un pou moins petite, et par les antennes moins grêles et un peu moins longues.

De Pensylvanic. - Je n'ai vu que deux exomplaires de 3. 6. 
cet insecte; ils mont élé communiqués par ir. le docteur Schaum.

18. Bryaxis impressa.

Lench. Zool. Misc., t. 3, p. 86.

Denny. Monog. Pselaph., p. 36, tab. 7, lig. 4.

Aubé. Monog. Psclaph., p. 31, tab. 81, tig. 1.

Lacord. Faun. entomol. desenv. de Paris, p. 567.

Erichs. K $e f$. der Mark Brand., t. 1, p. 270.

lleer. F'tun. Coleopt. Helvet., pars. 1, p. 358.

Pselaphus impresssus. Panz. Faun. Germ., 89, 10.

lieich. Monog. Pselaph., p. 58, tab, 2, fiğ. 15.

Vigra, nilidula, elytris rufis. Thoracis fossula intermedia minimi,

lateralibus mullo majoribus.

Has. Tibie intermedis spinule minimu intus ad apicem instructis.

$$
\text { Long. } 14 \text { mill. }
$$

Il est très-commun dans les prés humides.

19. Bryaxis Goryi.

Aubé. Monog. Pselaph., p. 30, tab. 83, firg. 4.

Castunco-picea, antentis pedibusque testuceo-ferrugincis. Thoracis

fossula intermedia tenuissima, lateralibus multo majoribus.

Has. Tibiis intermedis spinula minime intus ad apicem instruclis.

Long. 11 [ร. mill.

De Culombic, Carthagènc. - Ciet insecte fait partie dles collections de MH. Gory et Reiche. 


\section{Bryaxis Lebasii.}

Piceo-castanea, antennis, pedibus abdomineque ferrugineo-piceis, pube levi vestita. Thoracis fossula intermedia minima, laleribus paulò majoribus.

Mas. Tibiis intermediis spinula minima intus ad apicem instruclis.

$$
\text { Long. } 11 \text { [ } 2 \text { mill. }
$$

Corps un peu allongé, d'un brun châtain assez foncé et légèrement pubescent. Tête marquée de trois impressions arrondies, deux sur le vertex et une autre un peuplus grande tout à fait en avant. Antennes un peu ferrugineuses, l'avant dernier article presque aussi fort que le suivant et sphérique (1). Corselet rétréci en avant et en arrière, presque ovoïde, ayant trois fossettes:l'uneassez petile au milieu, près de la base, une autre de chaque côte un peu plus grande, placée tout à fait en dehors et presque sur le flanclui-même. Elytres un peu ferrugineuses, assez convexes, marquées d'une strie suturale et d'une autre partant du milieu de la base et n'atteignant pas l'extrémité. Abdomen assez convexe, le premier segment un peu plus long que le suivant. Pattes ferrugineuses.

Il ressemble un peu au $\boldsymbol{B r}$. Goryi, mais il est plus grand et couverı d'un petit duvet grisâtre qui ne se retrouve pas dans le premier.

De Colombie. - Il fait partie de la collection de M. Reiche.

b. Antennes irrégulièrement claviformes.

* Antennes irrégulières dans les deux sexes.

21. Bryaxis antennata.

Aubé. Monog. Pselaph., p. 31, tab. 84, fig. 2.

(1) Ce caractère est-il spécifique ou sexuel? Je ne sais, n'ayant pu observer qu'un seul individu de ce.Bryaxis. 
Lacord. Faun. cntomol. des env. de Paris, p. 567.

Heer. Faun. Coleopt. II elvet., pars. 1, p. 3 š

Nigra, nilidula, clytris rufis, pedibus ferrugineis. Antennarum urliculis $7-9$ inlus acutis, 10 quadralo.

Ias. Tibiis intermediis spinula minima, apice instructis.

$$
\text { Long. } 11 \text { [2 mill. }
$$

Il est assez rare el se rencontre dans les prés humides.

\section{Bryaxis heterocera.}

Virm-picea, nilidula, elytris abdomineque rufis, pedibus rufo-ferru

gineis. tnlennarum articulis $5-6-7-10-11$ majoribus.

Mas. Tibiis intermediis spinula minima apice instruclis.

$$
\text { Long. } 13 \text { [4 mill. }
$$

Corps peu allongé, noirâtre. Tète marquée sur le vertex de deux impressions arrondies et d'une autre un peu plus grande tout à fait en avant. Antennes noirâtres, ferruginouses à la base: le premier article assez lonğ, sub·cylindrique, le second à peu près du même diamètre transversal mais sphérique, les troisième et quatrième un peu plus étroits, les cinquième, sixième et septième beaucoup plus gros, presque sphériques, mais cependant un peu déprimés à la base et au sommet, les huitième et neuvième très-petits et lenticulaires, le dixième et le onzième assez forts et formant la massue, le dernier deux fois environ aussi long que le précédent et pyramidal. Corselet et élytres comme dans le Br. antemata. Abdomen rougeâtre, assez convexe, le premier segment deux fois aussi long que le second. Pattes assez longues, ferrugineuses; les jambes plus pâles; les tarses testacés. 
Il a été pris aux environs de la Calle, en Algérie, par M. Lucas, qui m'en a sacrifié un exemplairn.

** Antennes irrégulières dans les mâles seulement.

\section{Bryaxis eucera.}

Rubro cinnamomea, nitidula. Thoracis fossula intermedia leviuscula, transversa, lateralibus maximis.

IIas. Antennarum articulis 5-6 majoribus, irregularibus, inlus spinulosis.

Long. $11_{1}^{2}$ mill.

Corps peu allongé, d'un testacé rougeâtre. Tête marquée de trois impressions arrondies, deux sur le vertex et une autre un peu plus grande tout à fait en avant. Antennes simples dans les femelles, très-irrégulières dans les mâles, avec le premier article cylindrique, le second sphérique, les troisième et quatrième très-petits, transversaux, le cinquième beaucoup plus gros que les autres, irrégulièrement semilunaire, avec une épine assez saillante à sa partie interne, le sixième un peu plus petit que le précédent, presque ovoïde et ayant également une petite dent dirigée en dedans, les trois suivants très-petits, les deux derniers un peu plus forts et formant la massue. Corselet presque ovoïde, avec une dépression transversale très-petite au milieu, près de la base, et deux impressions arrondies, très-grandes, placées sur les côtés. Elytres assez convexes, marquées d'une strie suturale et d'une autre partant de la base et n'atteignant pas tout à fait l'extrémité. Abdomen assez convexe, le premier segment deux fois aussi long que le suivan'. Paltes de la même couleur que le corps. 
De Porto-Rico. - Il fail partie de la collection de M. Reiche. J'en ai également vu quelques individus qui m’ont été communiqués par MM. Kunze et Mærkel.

II. Une seule fosselte sur le corselet.

\section{Bryaxis levicollis.}

Rufo-cinnamomee. Thorace subgloboso, fossule minima unicu in medio ad basin impresso.

Mas. Tibiis intermediis spinula, minima inlus ad apicem instructis.

$$
\text { Long. } 11 \text { [ృ mill. }
$$

Corps à peine allongé, d'un rouge testacé, assez luisant. Tête un peu déprimée avec deux petites impressions arrondies, peu senties, sur le front. Corselet presque globuleux ayant une seule petite fossette arrondie sur le milieu, près de la base. Elyıres assez convexes, marquées d'une strie suturale et d'une autre partant du milieu de la base et n'alteignant pas l'extrémité. Abdomen un peu déprimé, le premier segment près de trois fois aussi long que le suivant.

De Colombic. - Il fait partie des collections de MM. Reiche, Dupont et Buquẹt.

\section{Tranus.}

Leach. Zool. Misc., t. 3, p. 84 .

Pselaphus. Payk. Faun. Suec., t. 3, p. 365 .

Antenne moniliformes, apice clavale, in luberculo frontali inserla. Palpi maxillares validi, arliculo terlio minimo, quarto maximo, securiformibus, intus fere angulatis.

$$
\text { Planch. III, n. } 9 .
$$

Corps très-peu allongé et assez convexe. Front lígère- 
ment prolongé en avant en un petit tubercule sur lequel sont insérées les antennes; labre transversal bisinueux et muni au milieu de deux pelits appendices membraneux en forme de $\mathrm{S}$ couchée; mandibules aiguës, ayant cinq ou six dents; mâchoires à divisions inégales, l'externe plus longue, elles sont ciliées en dedans; palpes maxillaires de quatre articles : le premier très-petit, le second très-allongé et en massue, le troisième très-petit, sécuriforme et presque triangulaire, le dernier très-large, sécuriforme, presque anguleux en dedans et terminé par un petit appendice membraneux; menton coupé presque carrément; languetle très-petite, se confondant avec les paraglosses qui sont assez grands et garnis d'une seule soie en dedans; palpes labiaux de deux articles : le premier très-petit, le second trois fois environ aussi long que le précédent et terminé par trois soies membraneuses, l'externe beaucoup plus longue que les internes qui sont très-petites et se touchent; antennes moniliformes, un peu renflées à l'extrémité. Corselet cordiforme. Abdomen rebordé. Pattes longues; cuisses un peu renflées; tarses de trois articles: le premier très-petit, les deux suivants presque égaux, le dernier terminé par un seul crochet.

Ils vivent dans les prés humides.

\section{Tychus niger.}

Leach. Zool. Misc., t. 3, p. 84.

Denny. Monog. Pselaph., p. 30, tab. 6, fig. 1 .

Aubé. Monog. Pselaph., p. 43, tab. 88, fig. 1.

Iacord. Faun, entomol. des env. de Paris, p. 575.

Pselaphus niger. Payk. Faun. Suec., t. 3, p, 365.

Reich. Monog. Pselaph., p. 36, tab. 1, fig. 5.

Gyl. Insect, Suec., t. 4, n. 266 
Niger, nilidus, antennis pedibusque rufis.

Mus. Antennurum; articulo quinto majore spherico; trochunteribus intermediis spinula armatis.

$$
\text { Long. 1 1/4 mill. }
$$

Assez commun dans les prairies: le mâle se rencontre moins fréquemment.

2. Tychus ibericus.

Vict. Motsch. Mém. de la Soc, des Nat. de Musi., t. IV, p. 319, fig. Ggg', Ihh' (1).

Tychus dichrous. Schmidt. De Pselaph. Faun. Prag., p. 18?

Niger, nilidus, anlemnis pedibustue testace is, elytris sanguine is.

Mas. Antennis simplicibus, trochanteribus intermediis spinula armatis.

\section{Long. 11 [ mill.}

Cet insecte se rapproche considérablement du $T$. niger et n'en est peut-être qu'une variété; cependant il est un peu plusfort: le mâle a les antennes simples et la femelle le tubercule antennifère un peu plus large.

Il se trouve dans l'Europe méridionale. J'ai cependant

(1) J'avais d'abord rapporté celle espèce au T. dichrous de Schmidt; mais d'après la note de M. Motschoulsky, insèrée au V vol. des mémoires de Moscou, dans laquelle il assure que son Tychus difrère de celui de M. Schmidt, j'ai adoptè la nomenclature de M. Motschouls$\mathrm{ky}$; il est cependant à regretter que cet entomologiste, puisqu'il considère ces deux espèces comme distinctes, n'ail pas analysé les caraclères propres à chacune d'elles ainsi que leur signes difrérentiels. Ciomme tous mes doutes ne sont pas levés au sujet de la nomenclature de cet insecte, j'ai cru devoir conserver la synonymie de Schmidt en l'accompagnant toutefois d'un signe dubitatif. 
pris un mâle de cetıe espèce aux environs de Paris. M. Lucas a également rapporté quatre individus femelles de l'Algérie (des environs de la Calle); ces derniers sont châtains avec l'abdomen noirâtre: ils sont probablement jeunes d'éclosion.

\section{Tychus castaneus.}

Rufo-castaneus, antennis pediousque pallide leslaccis. Capitis tubcrculo antennifero distinclius diviso.

Long. 1 mill.

Corps légèrement déprimé, d'un brun châlain assez brillant et recouvert de poils épars. Tête arrondie, offrant en avant deux petits tubercules à la partie inférieure desquels sont insérées les antennes; celles-ci d'un testacé pâle. Ciorselet cordiforme, assez fortement rétréci en arrière, dilaté au milieu environ, marqué tout à fait en arrière d'une petite impression arrondie, très-peu visible, et d'une ou deux autres de chaque côté, beaucoup moins perceplibles encore. Elytres assez fortement élargies en arrière et marquées d'une strie le long de la suture et d'une autre partant du milieu de la base et n'atteignant pas l'extrémité. Pattes testacées.

Il a la plus grande analogie avec le $T$. ibericus, surtou avec la variété rapportée d'AIgérie par M. Lucas; mais il est moitié plus petit; son tubercule antennifère est $\mathrm{cn}$. tièrement divisé en deux; la tête est plus arrondie et moins prolongée en avant; les antennes sont relativeplus courtes; le dernier article est presque sphérique, à peine ovoïde et les intermédiaires sont plus serrés, enfin il est d'une seule couleur.

Je n'ai vu que deux individus de cette espèce, l'un 
nppartient à M. le Marquis de la Ferté-Senectère, et a élé pris en Espagne, l'autre fait partie de ma propre collec. tion $\mathrm{ct}$ vient de Sicile. Je pense que ce sont deux femelles.

\section{Tychus tuberculatus.}

Tychus Dichrous. Schmidt. De Pselaph. Faun. Pragensis, p. 18 ?

Niger, nilidus, antennis pedibusque lestaceis, clytris sanguineis. Capilis luberento antennifero altero tuberculo anticè bifido tecto.

Long. 14$]^{4}$ mill.

Corps un peu allongé, d'un noir as:ez brillant et recouvert de très-petits poils épars. Tête offrant sur le fromt, au dessus du tubercule antennifère, un prolongement tuberculeux dirigé en avant, où il est échancré au milieu et garni de petits poils jaunâtres; antennes testacées. Corselet cordiforme, rétréci en avant el en arrière et dilaté un peu arant le milieu; il est marqué tout à fait en arrière, Ic long de la base, d'une petite impression arrondie, très-peu visible, et d'une ou deux autres de chaque cûté, beancoup moins perceptibles encore. Elytres d'un rouge pâle un peu rembruni à la base; clles sont à peine élargies en arrière et marquées d'une strie le long de la sulure et d'uncatıtre partant du milieu de la base et n'atleignant pas l'extrémité. Abdomen noir. Pattes testacées.

Cette espèce russemble beaucoup au $T$. ibericus; mais il sien distingue essentiellement, ainsi que du $T$. niger, par son lubercule frental.

Je n’ai vu que deux individus femelles de cet insecte, lous deux pris en France, l'un à Chinon par li. He marquis de la Ferté-Sénectère, et l'autre au Mans par M. An- 
jubault, qui l'a récolté l'hiver sous des débris de végétaux apportés, je crois, par la Sarthe.

\section{Bxthinus.}

Leach. Zool. Misc., t. 3, p. 82.

Arcopagus. Leach. Zool. Misc., t. 3; p. 83.

Pselaphus. Panz, Faun. Germ., p. 99.

Antenna moniliformes, apice clavala, in fossula laterali inserta. Palpi maxillares elongati, articulo ullimo securiformi.

\section{Planch. 1II, n. 8.}

Corps peu allongé et convexe. Tête offrant de chaque côté du front une petite cavité pour l'insertion des antennes; labre transversal coupé presque carrément en avant et muni au milieu de deux pelits appendices membraneux à peine visibles; mandibules aiguës, avec quatre à cinq dents; mâchoires à divisions inégales, l'externe beaucoup plus longue : elles sont ciliées en dedans; palpes maxillaires de quatre articles : le premier très-petit, le second très-long et claviforme, le troisième petit et un peu triangulaire, le dernier très-grand, sécuriforme, et terminé par un petit appendice membraneux ; menton coupé presque carrément; languette très-petite se confondant avec les paraglosses qui sont très-grands, aussi longs que les palpes et garnis en dedans de soies. rares et écartées; palpes labiaux de deux articles: le premier trèspetit, le second trois fois environ aussi long et terminé par deux soies membraneuses, l'externe un peu plus lon. gue; antennes moniliformes, un peu renflées à l'extrémité, avec le premier ou le second article généralement plus ou moins saillant en dedans dans les mâles. Corselet 
cordiforme, convexe et marqué en arrière d'une petite strie demi-circulaire. Elytres convexes et ponctuées. Abdomen très-étroit, rebordé. Pattes assez longues; les cuisses un peu renflées, généralement beaucoup plus dans les mâles; tarses de trois articles : le premier très-petit, les deux suivants très-longs, à peu près égaux, le dernier cependant un peu plus court, plus grêle et terminé par un seul crochet.

Ces insectes se rencontrent dans les détritus de végétaux, le bois pourri et sous les écorces.

Les mâles seuls des Bythinus sont aîlés, les femelles sont aptères. Cependant dans le $B$. nigripennis il existe des ailes dans les deux sexes. Ces observations sont dues à MM. Mierkel et Schaum, qui les premiers ont signalés ces fails. J'ai moi-même vérifié sur quelques espèces la vérité de cette assertion, et ayant dissiqué un très-grand nombre de $B$. bulbifer, le seul que nous trouvions trèscommunément, j’ai observé que généralement les mâles avaient des ailes propres au vol; mais j'en ai cependant rencontré quelques-uns dont les ailes, en raison de leur peu d'étendue, ne peuvent certainement pas leur permettre de s'élever dans l'air.

\section{Antemnes semblables dans les deux sexes.}

\section{Bythinus clavicomis.}

Aubé. Monog. Pselaph., p. 40, pl. 87, fig. 2.

Erichs. Kof. der Mrarck Brand., t. 1, p. 275.

Heer. Faun. Coleopt. II elvet., pars. 1, p. 360.

Pselaphus clavicornis. Panz. Faun. G(rm., 99, 3.

Reich. Honog. Pselaph., p. 10, 1. 1, fig. 7 (mâte).

Gyl. Ins. Suec., t. 4, p. 229. 
Arcopagus clavicornis. Leach. Zool. Misc.; t. 3, p. 84. Bythinus glabricollis. Erich. Kaf. der Mark Brand., t. 1, p. 275 (1)?

Pselaphus glabricollis. Reich. Monog. Pselaph., p. 43, tab. 1, fig. 8. (femelle.)

Rufo-piceus, elytris obscurioribus, antennis pedibusque rufo-testaceis.

MIas. Tibiis anterioribus intus denticulatis.

$$
\text { Long. } 11 \text { [3 mill, }
$$

Cet insecte est encore très-rare et le petit nombre d'individus que j'ai eu à ma disposition ont été pris en Saxe et m'ont été communiqués par MM. Schaum, Kunze et Mærkel.

\section{Bythinus? nigriceps.}

Kunzea nigriceps. Leach. Zool. Journ.; t, 2, p. 448. Corpore tolo ferrugineo, antennis pedibusque pallidioribus, capile

(1) Je liens de MI. le docleur Schaum, la nole suivante qu'il a eu la bonté de me communiquer et que je donne ici textuellement:

" J'ai vu dans la colleclion de M. Kunze tous les individus sur lesquels Reichembach a décrit son Ps. clavicornis, et tous sont des mâles. (M. Erichscu lui-même dit ne connaître que ce sexe). Je tiens également de M. Kunze, trois individus vus par Reichembach el décrits par lui comme glabricollis, qui sont tous trois des fenelles du clavicornis. D'après cette observation et ce que dit M. Erichson sur le glabricollis, il est plus que probable que ce dernier a décrit comme mâle de celte dernière espèce un clavicornis mâle dont les cuisses sont peu renflées comme cela arrive quelquefois el comme sa propre femelle, celle du clavicornis qu'il avoue lui-même ne pas connaître. )

En raison de la nole ci-dessus, j'ai cru devoir supprimer le $B$. glabricollis. 
nigrescente. Antennarum articulo primo in utroque sexu interne abruple dilalalo.

IIabilat in Alpibus marilimis, in sylvis penestribus rartssima. Dom. Fabre, mas el fem. in copulatione capti. (I.cach.)

11. Antennes dissemblables dans les deux sexes.

A. Premier article des antennes des muiles prolongé en dedans, le second cylindrique.

* Corselet très-visiblement ponctué.

3. Bythinus puncticollis.

Denny. Monog. Pselaph., p. 26, tab. oั, fig. 3.

Curtis. Brit, entom., t. 9, n. 422 (1)?

Aubé. Monog. Pselaph., p. 41, tab. 87, fig. 4 (femelle).

Lacord. Faun, entomol. des env. de Paris, pag. 572 (femelle).

Erichs. Kaf. der Mark Brand., t. 1, p. 276.

Heer. Faun. Coleop. II elvet., pars. 1, p. 360.

Bythinus Chevrolati. Aubé. Monog. Pselaph., p. 41, tab.87, f. 3 (mâle).

Bythinus regularis. Schmidt.De Pselaph. Faun. Pragens., p. 28 (2).

Rufo piceus. Thorace cordalo, dense punclato, fere opaco, Mas. Antevinarum arliculo primo intus ad apicem angulatim pro-

(1) Je conserve quelque doute sur la synonymie de Curlis et je crois que l'insecte qu'il a figuré doit plutôt se rapporter au $B$. $M$. gripennis.

(z) M. Schaum m'a assuré avoir vu dans !a collection de M. Schmidt lui-mème, le type de celte espèce qui doil être rapporlé au puncticollis femelle, malgré le silence que garde M. Sihmidt sur la ponctuation du corselet,

$2^{\text {e }}$ Série, том 1 . 
ducto; libiis anterioribus intus denticulatis: femoribus crassiusculis.

Long. 1 mill.

Il se trouve en France, en Angleterre et en Allemagne.

4. Bythinus validus.

Rufo-piceus. Thorace globoso, spar'sim punclalo, nilidulo. Mas. Antennarum articulo primo intus ad apicem angulatim producto; libiis anterioribus intus denticulalis; femoribus valdè incrassatis.

\section{Long. 11 [5 mill.:}

Corps très-peu allongé el très-convexe, d'un rouge un peu brunâtre. Tète finement reticulée, avec une impression demi circulaire qui fait paraître le front et les côtés un peu élevés; antennes lestacées, très-courtes, avec le premier article assez gros, offrant à son extrémité antérieure et interne une petite saillie angulaire. Corselet trèsconvexe, presque globuleux, couvert de points épars et assez rapprochés et marqué tout à fait en arrière d'une petite strie demi-circulaire. Elytres et abdomen comme dans le B. puncticollis, mais plus convexes. Pattes testacées; les cuisses des mâles très-renflées et les tibias antérieurs offrant en dedans oc un peu avant leur extrémité une dent très-petite.

Il ressemble considérablement au B. puncticollis, mais il est un peu plus grand et beaucoup plus convexe; son corselct est presque globuleux, couvert d'une ponctuation un peu moins serrée, et ses cuisses sont beaucoup plus renflées dans le mâle, seul sexe que j'ai vu.

Je possède dans ma collection un individu de cette es- 
pèce dont je ne connais pas la patrie, et j'en ai vu un autre que m’a communiqué M. Schaum et qui a été pris ì Cassel par M. Riehl.

Je ne sais si ce Bythinus par la présence ou l'absence des ailes dans les femelles se rapproche plus du B. puncticollis que du $B$. nigripennis, puisque je n'ai euà ma dispo. sition que deux mâles.

\section{Bythinus nigripennis.}

Rufus. Elytris piccis. Thorace cordato, dense punctato, fere opaco. Mas. Antennarum arliculo primo valido, intus rotundatim produrto, libiis anterioribus simplicibus.

\section{Long. 1 mill.}

Corps très-peu allongé et assez convexe, d'un testacé rougeâtre. Tête finement reticulée et marquée entre les yeux de deux petites impressions arrondies; antennes testacées, avec le premier article très-robuste, un peu plus étroit à sa base et très-saillant en dedans, où, chez le mâle, il est arrondi ; il est cylindrique dans la femelle. Corselet assez convexe, corliforme, couvert de points très-fins et très-rapprochés, ct marqué tout à fait en arrière d'une petite strie demi-circulaire. Elytres noirâtres, ponctuées el striées comme dans le B. puncticollis. Abdomen et pattes également comme dans ce dernier, seulement les tibias antérieurs sont simples et n'offrent pas de petite dent à leur extrémité interne.

Cet insecte a été signalé pour la première fois par M. Mærkel, qui l'a trouvé à Pirna, en Saxe. J'en ai aussi vu quelques individus venant d'Angleterre. Je n'ai aucun renseignement sur sa manière de vivre. 
** Corselet sans ponctuation bien apparente.

\section{Bythinus crassicornis.}

Vicr. Motsch. Mém. de la Soc. des Nat. de Mosc., I. IV, p. 317, tab. 11, fig. E.e. (mâle).

Bythinus longipalpis (1). Vict. Motsch. Mém. de la Soc. des Nat. de Mosc., t. IV, p. 318, tab. 11, fig. F. f. (fcmelle).

Piceus, antennis pedibusque rufo-testaceis; elytris punctura attrila tectis.

Mas. Antennarum arliculo primo intus ad apicem angulatim producto; tibiis anterioribus intus denliculatis; femoribus crassiusculis.

Long. 2 mill.

11 a été trouvé par M. Motschoulsky sous les écorces des arbres dans les steppes du Caucase; il se trouve aussi en Autriche.

\section{Bylhinus femoratus.}

mufo-piceus, antennis pedibusque rufo-testaceis; elytris obscurioribus valdè punctalis, punclis fere in lineis rectis disposilis. Mas. Antennarum articulo primo intus ad aptcem denticulalo; tibiis anterioribus et posticis intus denticulatis; femoribus valdè incrassatis.

\section{Long. 2 mill.}

Corps un peu allongé el assez convexe, d'un brun de

(1) M. Molschoulky paraît avoir contondu plusieurs femelles sous la dénominalion de longipalpis, car il rapporte, dans le Bullelin de la Sociélé des naturalisles de Moscon pour 1840, son 8 . longipalpis à 
poix un peu rougeâtre. Tête lisse et marquée entre les yeux de deux petites impressions arrondies; antennes testacées, avec le premier article, chez le mâle, assez allongé, assez fort et armé tout à fait à son extrémité interne d'une petite dent saillante; il est très-probablement cylindrique dans la femelle. Corselet cordiforme rétréci en avant et en arrière et dilaté un peu avant le milieu; il est marqué en arrière d'une petite strie demi-circulaire. Elytres noirâtres et couvertes de points fortement enfoncés et presque disposés en lignes longitudinales, striées et marquées comme dans ses congénères. Pattes d'un testaté rougeâtre; les cuisses du mâle fortement renflées, et les tibias antérieurs et postérieurs armés en dedans et près de leur extrémité d'une petite dent assez saillante.

Je n'ai vu qu'un seul individu mâle de cette espèce; il appartient à M. le docteur Schaum qui l'a reçu d'Autriche.

Il ressemble beaucoup au $B$. crassicornis dont il a la taille: il en diffère par le premier article des antennes, dont la saillie anguleuse est moins saillante et plus étroite; par ses élytres couvertes de points enfoncés, beaucoup plus marqués et presque disposés en lignes; et enfin par ses pattes dont les cuisses sont très-fortement renflées et les tibias antérieurs et postérieurs armés d'une petite dent. Cette différence n'est établie que sur le mâle, seul sexe que j'ai eu à ma disposition.

\section{Bythinus bulbifer.}

Aubé. Monoy. Pselaph., p. 37, tab. 86, tiğ. 2 (mâle).

la femelle du $b$. securiger, et jaien ce moment sous les yeux deux individus venant de M. Motschoulsky lui-même, portant chacununc étiquette de sa propre main avec le nom de $B$. longipalpis et qui : ont deux femelles, l'un de son $B$. crassicornis el l'autre du B. Curlisii. 
Lacord. Faun. entomol. des env. de Paris, p. 571 (mâle). Erichs. Kaf. der Mark Brand., t. 1, p. 273.

Heer. Faun. Coleopt. Helvet, pars. 1, p. 359.

Pselaphus. buibifer. Reich.Monog. Pselaph., p.37, 1ab.1, fig. 6.

Gyl. Insect. Suéc., t. 4. p. 228 (mâle).

Arcopagus bulbifer. Leach. Zool. Illisc., t. 3, p. 84.

Denny. Monog. Pselaph., p. 24, tab. 5, fig. 1.

Pselaphus glabricollis. Gyl. Ins. Suec., t. 4, pag. 229 (femelle).

Bythinus glabricollis. Aubé. Monog.Pselaph., p. 38, t. 86, fig. 3 (femelle).

Lacord. Faun, entomol. des env. de Paris, p. 357 (femelle).

Nigro.piceus, antennis pedibusque dilutioribus.

IIas. Antennarum arliculo primo valdè incrassato ad basin angustato, intus bisinualo et apicem denticulato; tibiis anterioribus intus denticulatis.

\section{Long. 11 I $\mathrm{mill}$.}

Il est très-commun dans les prairies, où il se tient caché pendant le jour au pied des herbes; on le rencontre le soir à leur sommet.

B. Premier article des antennes des mâles cylindroide, le second prolongé en dedans.

9. Bythinus Curtisiii.

Leach. Zool. Misc, , t. 3, p. 83.

Denny. Monog. Pselaph., p. 20, tab. 3, fig. 1. Aubé. Monog. Pselaph., p. 20, tab. 3, fig. 1.

Latcord. Faun, entomol, des env. de Paris, p. 569. 
Erichs. Kaf. der Marli Brand., t. 1. p. 274.

Heer. Faun. Coleop. Helvet., pars. 1, p. 360.

Bythinus Curtisianus. Leach. Zool. Jour., t. 2, p. 446.

Castaneo-piceus, antennis pedibusque rufo-testaceis.

Mas. Intennarum articulo secundo sphcrico, intus dentato; tibiis

anterioribus intus denticulatis.

\section{Long. 11/4 mill.}

Il se rencontre dans le bois pourri, sous les écorces des arbres morts et dans les détritus de végétaux : il n’est pas très-commun.

10. Bythinus nodicornis.

Aubé. Monog. Pselaph., p. 37, tab. 86, tig. 1.

Heer. Faun. Coleopt. Helvet., p. 359.

Bythimus Sternbergi, Schmidt. De Pselaph. Funn. Prayens., p. 27 (1)?

Castaneo-piceus, antenmis pedibusque rufo-lestaceis.

IIas. Antennarum articulo secundo cuneiformi transersali, intus producto; tibiis anterioribus intus denliculatis.

$$
\text { Long. } 11 \text { | } 4 \text { mill. }
$$

Le petit nombre d'individus que j'ai pu voir ont été prix en Saxe par M Mrrkel.

(1) L'individu typique et unique de celle espèce est perdu, d'après l'assurance que m'en a donné M. le docteur Schaum, de sorte qu'il sera á l'avenir bien difficile de rapporler avec certilude à celte espèce les individus que l'on pourra soupçonner lui appartenir. D'après la figure qu'en donne Schmidt, ce Bythinus pourrait bien n'être que le nodicornis. 
Leach. Zool. Misc., t. 3, p. 83.

Denny. Monng. Pseluph., p. 21, tab. 3, fig. 2.

Aubé. Monog. Pselaph., p. 36, tab. 85, fig. 4 (mâle).

Lacord. Faun, entomol. des env, de Paris, p. 570.

Erichs. Kaef. der Mark Brand., t. 1, p. 272.

Heer. Faun. Coleopt. Helvet., pars. 1, p. 359.

Pselaphus securiger. Reich. Monog. Pselaph., p. 45, tab. 1, tig. 9.

Bythinus macropalpus. Aubé. Monog. Pselaph., pag. 39, tab. 86, fig. 4 (femelle).

Bythinus globulipalpus. Aubé. MIonog. Pselaph., pag. 39, tab. 87, fig. 1 (1).

Nigro-piceus, antennis pedibusque rufo-testaceis.

Mas. Antennarum arliculo secundo inlus compresso, securiformi; $i$ biis omnibus simplicibus.

\section{Long. 9 [10 mill.}

Très-commun dans les prés humides.

12. Bythinus Burellii.

Denny. Monog. Pselaph., p. 22, tab. 4, fig. 1.

Erichs. Kaef. der Mark Brand., t. 1, p. 271.

Heer. Faun. Coleopt. Helvet., pars 1, p. 359.

Bythinus luniger. Aubé. Monog. Pselaph., p. 35, tab. 85, fig. 2.

Lacord. Faun. entomol. des env. de Paris, p. 570.

(1) Le B. globulipalpus de notre monographie, est bien certainement une femelle de celte espèce dont les palpes ont été vus en raccourci, 
Nigro-piceus, antennis pedibusque rufo-lesluceis.

Mas. Antennarum articulo secundo lunato, angulis duobus aculis, intus productis; tibiis omnibus simplicibus.

$$
\text { Long. 9,10 mill. }
$$

Cet insecte est très-rare : il se trouve en France, en Allemagne et en Angleterre. J'en ai pris moi-mème quelques individus aux environs de Paris, en fauchant le soir dans les prés frais.

\section{Bythinus uncicornis.}

Bythinus Burellii. Aubé. Monog. Pseluph., p. 35, tab. 83, fig. 3.

Schmidt. De Pselaph. Faun. Pragens., p. 24?

Nigro-piceus, antennis pedibusque rufo-testaceis.

Mas. Antennarum articulo secundo subquadrato, vix lunato, angulo antico aculo, postico recto, inlus prodactis; libiis omnibus simplicibus.

\section{Long. 9[10 mill.}

Je possède un seul individu mâle de cette espèce; il a été pris à Marseille par M. Solier, en secouant une vieille caisse qui était depuis longlemps dans sa cave.

Quoique cette espèce ait le plus grand rapport avec la précédente, je la crois cependant distincte. Le second article des antennes du mâle est moins semilunaire, son bord interne n'est pas échancré, son angle antérieur est très-aigu et le postérieur presque droit. J'ai de la peine à croire que cette différence dans la forme de cet article ne soit pas une différence spécifique et soit simplement due à une variété.

Si le genre Bythinus, tel que nous venons de le passer en revue, offre des caractères très-saillants pour distinguer les mâles entre eux, il n'en est pas ainsi des femel. 
les dont la séparation tranchée me parait impossible dans certaines espèces; ainsi, je crois qu'il est fort difficile de distingueur entre elles et d'une manière sûre les femelles des $\boldsymbol{B}$. Curtisii, nodicornis et bulbifer, ainsi que celles des B. Burellii, haniger et uncicornis.

Trimium.

Aubé. Mlonog. Pselaph., p.44.

Pselaphus. Reich. Monog. Pselaph., p. 47.

Euplectus. Denny. Monog. Pselaph., p. 18.

Corpus elongatum, cylindricum. Antennce monitiformes, apice clavalce, in fossula laterali inserta, articulo ultimo maximo. Palpi maxillares elongaluli, articulo ultime leviter intus ampliato, securiformi.

Planch. III, n. 11.

Corps allongé, cylindroide. Tête offrant de chaque côté du front une petite cavité pour l'insertion des antennes; labre transversal à peine arrondi en avant et muni au milieu de deux petits appendices membraneux peu visibles; mandibules aigues, avec cinq à six dents; mâchoires assez robustes, à divisions inégales, l'externe un peu plus longue : elles sont ciliées en dedans; palpes maxillaires médiocrement allongés, de quatre articles : le premier trèspetit, le second un peu allongé, claviforme, le trojsième presque globuleux, le dernier un peu dilaté en dedans, sécuriforme et terminé par un petit appendice membraneux; menton un pou échancré; languette très-petite, se confondant avec les paraglosses qui sont assez graads, de la longueur des palpes labiaux, élargis à leur extrémité et munis en dedans d'une seule petite soie; palpes labiaux de dcux articles : le premier très;petil, le second trois fois 
au moins aussi long que le précédent et terminé par deux soies membraneuses, l'externe un peu plus longue; antennes moniliformes, très-renflèes à leur extrémité, la massue occupant plus du tiers de leur longueur. Corselet cordiforme. Elytres assez convex s. Abdomen rebordé. Pattes assez longues; cuisses un peu renflées; tarses de trois articles : le premier très-petit, le second très-long, le dernier un peu moins long que le précédent et terminé par un seul crochet.

Les insectes de ce genre vivent dans les détritus de végétaux.

\section{Trimium brevicöne.}

Aubé. Monoy. Pselaph., p. 14, tab. 88, fig. 2.

Lacord. Faun. entomol. des env. de Paris, p. 574.

Pselaphus brevicornis. Reich. Monog. Pselaph., pag. 47, tab. 1, fig. 10.

Gyl. Insect. Suec., 1, 4, p. 230.

Euplectus brevicornis. Denny. Monog. Pselaph., pag. 18, tab. 2 , fig. 4.

Erichs. Kaef. der Marli Branul., t. 1, p. 280.

Heer. Faun. Coleopt. Helvet., pars 1, p. 361.

Irufo-ca luneus; untennis pedibusque testaceis. Capile sulcis duobus obliquiis anticè convergentibus impresso.

\section{Long. 1 mill.}

On le rencontre, mais peu fréquemment, dans les détritus de végétaux et surtout dans les vieux fagots.

\section{Trimium beioceplialium.}

Euplectus leiocephalus. Aubé. Monog. Pselaph., pag. 60, tab. 93, fig. 5 . 
Rufo-caslaneus, antennis pedibusque teslaceis. Capite levi.

$$
\text { Long. } 3 \text { [4 mill. }
$$

Je n'ai vu qu'un seul individu pris à Toulon.

Il ressemble beaucoup au $B$. brevïcorne. mais il est beaucoup plus petit; ses antennes sont relativement beaucoup plus longues, et sa tête n'offre aucune impression.

\section{Euplectus.}

Leach. Zool. Misc., t. 3, p. 80.

Pselaphus. Illig. Kaf. Preus., t. 1, p. 290.

Anthicus. Fab. Sys. Eleut., t. I, p. 294.

Corpore elongato, depressiusculo. Antennce moniliformes, apice cluvala, in fossula laterali inserte. Palpi maxillares elongati, articulo ultimo fusiformi.

\section{Planch. III, n. 10.}

Corps allongé et déprimé. Tête offrant de chaque côté du front une petite fossette pour l'insertion des antennes; labre transversal, bisinueux en avant et muni au milieu de deux petits appendices membraneux; mandibules aiguës avec cinq ou six dents; mâchoires à divisions inégales, l'externe beaucoup plus longue; elles sont ciliées en dedans; palpes maxillaires médiocrement allongés, de quatre articles: le premier très-petit, le second un peu allongé el claviforme, le troisième presque globuleux, le dernier fusiforme et terminé par un petit appendice membraneux; menton coupé presque carrément; languette très-petite, se confondant avec les paraglosses qui sont grands, de la longueur des palpes labiaux, et munis en 
dedans de soies rares et écartées; palpes labiaux de deux articles : le premier très-petit, le second trois fois aussi long que le précédent et terminé par deux soies memhraneuses, l'externe un peu plus longue; antennes moniliforme et un peu renflées à leur extrémité. Corselet cordiforme ou arrondi. Elytres déprimées. Abdomen rebordé. Pattes assez longues; les cuisses un peu renflées; tarses de trois articles : le premier très-petit, le second et le troisième beaucoup plus long et égaux entre eux; ce dernier terminé par un seul crochet.

Les Euplectus vivent dans les détritus de végétaux.

1. Corselet avec trois fossettes réunies par un sillon transversal.

A. Corselet marqué d'une impression en avant de la fossette médiane de la base.

1. Euplectus sulcicollis.

Erichs. $\boldsymbol{K}(\boldsymbol{x})$. der Mark Brand., 1. 1, p. 277.

Pselaphus sulcicollis. Reich. Monog. Pselaph., pag. 67, tab. 2, fig. 17.

Gyl. Ins. Suec., t. 4, p. 234.

Pselaphus dresdensis. Illig. Kaf. Preus., p. 290, 1.

Anthicus dresdensis. Fab. Syst. Eleut., t. 1, p. 293.

Bryaxis sulcicollis. Curtis. Brit. entom., 7, n. 315,

Rufo-testaceus, pubescens. Capile utrinque sulcalo, anticè late impresso. Thorace anticè canaliculato. Elylris subtilissime reticulatopunctatis, pube levissima dense velutinis, opacis.

$$
\text { Long. } 2 \text { 2,3 mill. }
$$

II se trouve en Saxe et surtout en Autriche; il est as- 
sez fréquent aux environs de Vienne. J'en possède un exemplaire pris dans les Alpes du Piémont, et qui m'a ćté donné par M. Je marquis de Brême. M. Anjubaulı l'a également pris aux environs du Mans, dans une vieille souche de charme, où se trouvaient aussi quelques $I I y r^{-}$ mica rubra.

\section{Euplectus Moerkelii.}

Euplectus sulcicollis. Aubé. Monog. Pselaph., p. 52, tab.91, fig. 1.

Lacord. Faun. entomol. des env. de Paris, p. 578.

Rufo-testaceus, pubescens. Gapile utrinque sulcato, anticè late impresso. Thorace canaliculato. Elytris subtile reticulato-punctatis, pube levi sparsim vestitis, nilidulis.

\section{Long. 21 [4 mill.}

Cette espèce diffère de la précédente surtout par sa taille beaucoup plus petite; cependant le corselet est plus rétréci en arrière, les élytres sont plus finement reticulées, couvertes d'une pubescence beaucoup moins serserrées, et elles sont légèrement luisantes, tandis qu'elles. sont ternes dans l'E. sulcicollis.

Il se trouve en France, en Saxe, en Hongrie et est assez fréquent aux environs de Vienne. Je l'ai dédié à M. Maerkel, auquel l'entomologie est redevable de la découverte d'un si grand nombre de petites espèces.

\section{Euplectus Kunzei.}

Rufo-brunneus; antennis pedibusque dilutioribus. Capile anticè late et in verlice punctis duobus impresso. Thorace brevissime canaliculalo. 
Long. 2 mill.

Corps asscz allongé, déprimé et d'un lestacé un peu brunâtre. Tête marquée en avant d'une tris-large dépression un peu plus profonde de chaque côlé en dedans des antennes et de deux points arrondis sur le vertex. Antennes un peu plus pâles. Corsulet cordiforme, avec trois impressions assez profondes; l'une au milieu près de la base, les deux autres sur les côtés; toutes trois róunies par un petit sillon transversal, en outre, il offre sur le disque un petit sillon t: ̀̀s-court qui n'alleint ni le sommet ni l'impression médiane de la base. Elytres dépri. mées, marquées d'une strie suturale et d'une autre qui parlant de la base atteint environ le milieu de la lon. gueur. Abdomen offrant sur les deux premiers articles unc petite impression transversale placée tout-à-fait en avant à leur point d'allache. Pattes testacées.

Il ressemble un peu a l' $E$. sulicollis dont il differe par sa taille plus petite, sa tête offrant deux points enfuncés sur le vertex, son corselet dont le sillon du disque st beancoup plus court et enfin par lablomen, dont les deux premiers segments offrent une petite impression.

Il se trouve en Styrie el en Suisst: il a été pris par M. Chevrier, aux environs de Genève.

\section{Euplectus Erichsoni.}

Valde clongatus, subparallelus, rufo-testaseus. Capite antici leviler reflexo, supra sulcis duobus longiludincilibus profunde impresso; sulcis anlicè et posticè in fossulis terminatis. Thorace canalieulato.

$$
\text { Long. } 2 \text { mill. }
$$

Corps fortement allongé, parallèle, déprimé et d'un testacé rougâtre. Tête avec le bord antíricur légèroment 
relevé et marquée de chaque côté d'un sillon profond, terminé en avant par une impression irrégulière, assez profonde et placée en dedans des antennes, et en arrière par une autre impression punctiforme, également assez profonde; le vertex est un peu élevé et lisse; les mandibules assez saillantes. Corselet cordiforme, avec trois impressions assez profondes, l'une au milieu près de la base, les deux autres sur les côtés, toutes trois réunies par un petit sillon transversal ; en outre, il offre sur le disque un petit sillon très-étroit, qui, partant en arrière de la fossette médiane, n’atteint pas tout à fait le sommet. Elytres déprimées, marquées d'une strie suturale et d'une autre strie, qui, partant de la base atteint environ la moitié de leur longueur. Abdomen à segments uniformes. Pattes un peu plus pâles.

Il a quelque analogie de taille avec le précédent, mais il est relativement plus allongé, beaucoup plus parallèle; la tête est autrement marquée; les mandibules sont plus saillantes; et enfin les premiers segments de l'abdomen n'ofirent aucune impression.

Je n'ai vu que quatre individus de cette espèce, tous quatre pris en Saxe par M. Mærkel.

\section{Euplectus Fischeri.}

Aubé. Monog. Pselaph., p. 54, tab. 91, fig. 3.

Euplectus Tischeri. Heer. Faun. Coleopt. Helvet., pars. 1, p. 362 (1).

(1) Il est vrai que lors de la publication de ma monographie des Psélaphiens, j'ai décrit cet Euplectus sous le nom de Fischeri tandis que j'aurais du lui assigner le nom de Tischeri, j'ai été trompé par la similitude de forme de la première lettre du nom qui m'avait été communiqué par M. Buquet, et j'ai pris le T majuscule pour un $\mathbf{F}$ également majuscule. Malgré cela M. Heer a eu tort de vouloir rétablir le nom de Tischeri, c'est multiplier la synonymie sans profit, aussi ai-je cru devoir maintenir mon premier nom. 
Rufo-teslaceus. Capilc sulcis duobus lateralibus profunde anticè convergentibus impresso; verlicè foveolato. Thorace canaliculato.

$$
\text { Long. } 1 \text { 1]2 mill. }
$$

Il se trouve en Saxe, et en Suisse aux environs de Genève.

\section{Euplectus Duponti.}

Aubé. Monog. Pselaph., p. 57, tab. 92, fig. 4.

Rufo-testaceus, subparallelus. Capile anticè fossula lata triangulari et in vertici punctis duobus impresso. Thorace brevissime canaliculato.

\section{Long. 1 1,2 mill.}

J'ai pris une seule fois et un seul individu de cette espèce dans du bois pourri à Fontainebleau; elle a quelques rapports dans la forme de la tête avec le Kunzei; mais elle est plus de moitié plus petite, plus déprimée et plus parallèle.

\section{Euplectus signalus.}

Aubé. Monog. Pselaph., p. 56, tab. 92, fig. 3.

Lacord. Faun. entomol. des env. de Paris, p. 581.

Erichs. Kaef. der Mark Brand., t. 1, p. 279.

Heer. Faun. Coleopt. Ilelvet., pars. 1, p. 362.

Pselaphus signatus. Reich. Monog. Pselaph., p. 73, tab. 2, fig. 22.

Gyl. Ins. Suec., t. 4, p. 239.

Euplectus Kirbyi. Denny. Monog. Pselaph., p. 11, tab. 2, fig. 1.

Aubé. Monog. Pselaph., p. 54, t.91, fig. 4.

Rufo-testaceus. Capite anticè transversim impresso el ulrinque profunde sulcato. Thorace in disco foveolato.

2. Serie, том. 1 . 
- Long. 114 mill.

Il est très-commun dans les détritus de végétaux.

8. Euplectus sanguineus.

Denny. MIonog. Pselaph., p. 10, tab. 1, fig. 2. Aubé. Ifonog. Pselaph., p. 55, tab. 92, fig. 1. Lacord. Faun. entomol. des env. de Paris, p. 580. Heer. Faun. Coleopt. Helvet., pars. 1, p. 362.

Piceus, antennis pedibusque teslaceis. Capile anticè transversim im presso et ulrinque profunde sulcato. Thorace in disco foveolato.

\section{Long. 11 I mill.}

Il est généralement un peu plus fort que le signatus dont il ne diffère presque que par la couleur; peut-être n'en est-il qu'une simple variété. Je l'ai pris plusieurs fois dans le fumier des couches à melons et jamais je ne l'ai rencontré ailleurs.

\section{Euplectus Karstenii.}

Denny. Mllonog. Pselaph., p. 12, tab. 1, fig. 3. Aubé. Monog. Pselaph., p. 56, tab. 92, fig. 2.

Lacord. Faun. entomol. des env. de Paris, p. 580.

Erichs. Kref. der Mark Brand., t. 1, p. 278.

Heer. Faun. Coleopt. Helvet., pars. 1, p. 363.

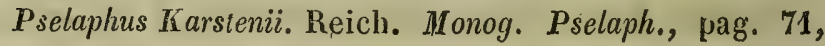
tab. 2. fig. 21.

Gyl. Ins. Suec., t. 4, p. 238.

Iufo-testaceus, capite thoraceque punctulatis. Capite anticè transversim impresso et utrinque sulcalo. Thorace in disco foveolato. 
Long. 1 mill.

Il se trouve assez rarement aux environs de Paris, dans les détritus de végélaux; mais il n'est pas rare en Alle. magne, et il est très-commun aux environs de Vienne.

Celte espèce est généralement plus petite que le signatus; cependant j'en ai sous les yeux quatre individus qui sont plus grands que ce dernier. J'ai pris l'un dans du fumier de couches, et les trois autres appartiennent à M. Mrrkel et à M. Schaum et ont été recueillis en Styrie. Je les ai examinés avec beaucoup de soin pour m'assurer s'ils ne pouvaient pas constituer une espèce distincte; mais je n’ai trouvé aucun caractère assez saillant pour me déterminer à les décrire sous un nọm différent.

\section{Euplectus Spinole.}

Rufo-lestaceus, elytris apice infuscalis, pedibus lestaceis. Capile thoraceque punctulatis. Capite sulcis duobus longitudinalibus anticè conjunctisimpresso; verticè anguste elevalo. Thorace in disco fovcolato.

\section{Long. 3[4 mill.}

Corps assez allongé, fortement déprimé et d'un testacé rougeâtre. Tète couverte d'une ponctuation très-fine et très-serrée, et marquée en dessus de deux impressions longitudinales, assez enfoncées et se réunissant en avant; l'espace compris entre ces deux sillons est relevé et trèsétroit. Corselet cordiforme, avec trois impressions assez profondes, l'une au milieu près de la base, les deux autres sur les côtés, toutes trois réunies par un petit sillon transversal; il offre en outre sur le disque une petite fossette allongée, placée tout-à-fait au devant de l'impression médiane; il est ponctué comme la tête, mais les points sont moins serrés, ce qui le fait paraître moins 
terne. Elytres déprimées, d'un testacé rougeâtre, avec l'extrémité assez largement rembrunie; elles sont marquées d'une strie suturale et d'une autre qui partant de la base n'atteint pas tout-à-fait le milieu. L'abdomen et les pattes comme dans le Karstenii.

Il ressemble beaucoup au Karstenii dont il n'est peutêtre qu'une variété; il est plus petit, plus déprimé; sa tête est couverte de points plus serrés, ce qui le fait paraître plus terne, et enfin ses élytres sont rembrunies à leur extrémité.

Je n'ai vu qu'un seul individu que je tiens de $\mathbf{M}$. Chevrier, qui l'a pris aux environs de Genève, et qui me l'a donné sous le nom que je lui conserve ici. M. Chevrier en possède encore un autre.

\section{Euplectus nanus.}

Piceus, elytris ferrugineo-piceis, antennis pedibusque testaceis. Capite-sulcis duobus longiludinalibus anticè conjunctis profunde impresso; verticè summo unipunctalo. Thorace in disco foveolato.

\section{Long. $11 / 2$ mill.}

Il est assez rare et se rencontre sous les écorces d'ar. bres et dans le bois pourri, en France, en Suisse et en Allemagne.

12. Euplectus piceus.

Vict. Motsch. Mém. de lä Soc, des Nat. de Mosc., t. IV, p. 320 , tab. XI, fig. I. i.

Depressus, piceus. Capile incequali, inter antennas carinula conspicua, transversa signalo; palpis, antonnis pedibusque testaceis. Thorace postice fovcolis tribus subconftuentibus, in medio disco impresso. 


\section{Long. 2]3 lig. - Larg. 1[6 lig.}

Il ressemble un peu à l'Eupl. namus, Reich., mais il est plus grand; la tête est plus large; le corselet un peu plus court; les élytres un peu plus longues et avec deux lignes imprimées plus longues. (Vict. Molsch.)

Je ne sais que penser de celte espèce que je n'ai pu me procurer.

B. Aucune impression sur le disque du corselet cn avant de la fossette médiane de la base.

\section{Euplectus ambiguus.}

Aubé. Monog. Pselaph., p. 58, tab. 93, fig. 2.

Lacord. Faun. entomol. des env. de Paris, p. 582.

Erichs. Ka\%. der Mark Brand., t. 1, p. 280.

Heer. Fann. Coleop. Helvet., pars. 1, p. 363.

Pselaphus ambiguus. Reich. IIonog. Pselaph., pag. 67, t. 2, fig. 19.

Gyl. Ins. Suec., 1. 4, p. 12.

Euplectus pusillus. Denny. Monog. Pselaph., p. 15, t, 2, fig. 2.

Aubé. Monog. Pselaph., p. 59, tab. 94, fig. 3.

Lacord. Faun. entomol. des env. de Paris, p. 582.

piccus, antennis pedibusque teslaceis. Capite sulcis duobus longiludinalibus, anticì conjunctis impresso.

\section{Long. 1 mill.}

Il est assez commun dans les prés: on le prend en fà chant le soir sur le sommet des herbes. 
14. Euplectus minutissimus.

Aubé. Monog. Pselaph., p. 59, tab. 93, fig. 4.

Angustus, piceus, antennis pedibusque testaceis. Fronte fossulis duabus rolundalis impressa.

IIas. Abdomine segmento ullimo spinula minima armato.

\section{Long. 9 [10 à 1 mill.}

Cet insecte est très-rare. Je n'en ai encore vu que six individus : un de Sicile et cinq pris en Saxe par M. Mærkel.

\section{Corselet à fossettes libres.}

15. Euplectus bicolor.

Denny. Monog. Pselaph., p. 17, tab. 2, fig. 3.

Aubé. Monog. Pselaph., p. 57, tab, 93, fig. 1.

Lacord. Faun. Entomol. des env. de Paris, p. 581.

Heer. Faun. Coleopt. Helvet., pars. 1, p. 363.

Pselaphus glabriusculus. Gyl. Ins. Suec., t. 4, p. 236.

Piceus, antennis pedibusque testaceis. Capite sulcis duobus longiludinalibus anticè convergentibus impresso. Thorace ad apicem foveolato el ulrinque ad marginem lineolato.

alas. Femoribus crassiusculis, libiis intermediis intus ad medium denticulatis.

\section{Long. 1 mill.}

Cet insecte est très-rare. Je n'en ai vu que trois exemplaires : deux pris par moi sous une écorce à Paris; l'autre $\mathrm{m}$ 'a été communiqué par M. Schaum sous le nom de gracilis de Grimmer : il l'a reçu de Styrie. 


\section{Euplectus REsterbrookianus (1).}

Leach. Zool. Journ.. t, 2, p. 445.

Corpore toto intense ferrugineo; antennis, palpis pedibusque pallidioribus; thorace ruguloso; elytris punctulatis.

Habitat in Danmoniæ nemoribus rarissimus. (Leach.)

\section{Euplectus Schmidtii.}

Mrerkel. Zeitschrift fur die entomol. von Germ., tom. V, p. 259.

Testaceus, nilidus, sublilissime pubescens, antennarum arliculo ul-

timo magno, securiformi, capite trigono, fronte foveolis duabus, thorace antice dilatato, posticè foveolis tribus, sulco transversali connexis.

$$
\text { Long. 1 } 1 \text { lig. (Mærkel.) }
$$

M. Mrrkel compare cet insecte avec monTrimium leiocephalum dont il diffère par les fossettes de la tête et la structure des antennes. Peut-être doit-il aussi rentrer dans le genre Trimium.

Il a été pris dans l'ile de Wollin avec la Formica rufa, par MM. Dieckhoff et Schmidt.

\section{DEUXIÈME SEGTION.}

Antennes de six articles.

\section{Guaviger.}

Preyssler. Ins. Boh., p. 68.

Clavifer. De Laporte. Etud. entomol., p. 137.

(1) Je cile ici celte esprece d'Euplectus quui très probablement n'est pas a sa place; mais la concision de la description ne me permet pas de lui assigner un rang dans les divisions que jai ètablies; peut-être même rentre-t-il dans une des especes que j'ai décrites. 
Antenno sex articulati, in fossula frontali inserta, articulo ultimo iruncato. Palpi maxillares brevissimi, uni-articulati. oculi nulli.

\section{Planch. III., fig. 12.}

Corps un peu allongé et assez convexe. Tête offrant tout à fait en avant et de chaque côté une petite fossette pour l'insertion des antennes; yeux nuls; labre presque demicirculaire; mandibules très-courtes, presque droites en dedans, ciliées à leur base et munies d'une très-petite dent à leur extrémité; mâchoires à division presque égales, l'externe cependant un peu plus longue; elles sont garnies de soies très-longues, onduleuses et qui font le panache; palpes maxillaires d'un seul article, muni à son extrémité de deux petits appendices membraneux, un peu arqués l'un en dessus et l'autre en dessous et figurant assez bien le boutoir d'un sanglier; menton très-largement arrondi; languette se confondant avec les paraglosses qui sont très-grands, très-larges, irrégulièrement triangulaires et garnis de soies très-longues, onduleuses et formant le panache; palpes labiaux d'un seul article, terminé par une longue soie membraneuse; antennes de six articles, le dernier tronqué. Elytres très-courtes, offrant à leur angle externe et postérieur un petiı pli garni de poils assez longs. Abdomen de cinq segments : les trois premiers réunis, sans suture apparente en dessus, mais très-visible en dessous; il offre à sa base et en dessus une très-large impression. Pattes assez longues et assez robustes; tarses de trois articles : les deux premiers extrêmement courts, le dernier très-long et terminé par un seul crochet.

Ces insectes vivent en société avec des fourmis qui ne sont pas toujours les mêmes pour la même espèce.

J'ai avancé dans les Annales de la Société entomolo- 
gique, page 227 de l'année 1842, à propos d'un travail sur le Langelandia anophthalma, que les Claviger étaient aptères; je suis obligé aujourd'hui de revenir sur cette déclaration. Ayant de nouveau soumis les Claviger testaceus et longicornis à un examen plus attentif, et employé à cet effet un instrument à fort grossissement, j'ai acquis la certitude que ces insectes sont bien réellement munis d'ailes, mais qui ne paraissent pas propres au vol, en raison de leur brièveté; elles sont elliptiques, sans ner. vures ni découpures, et entièrement recouvertes de petites soies épineuses très-rapprochées les unes des autres.

\section{Claviger testaceus.}

Preyssler. Ins. Boh., p. 68, tab. 3, fig. 5. a. b.

Panz. Faun. Germ., 49, fig. 8.

Claviger foveolatus. Müller. In Germ. Mag., t. 3, p. 69. Aubé. Monog. Pselaph., p. 61, tab. 94, fig. 1.

Heer. Faun. Coleopt. Heliet., pars. 1, p. 364.

Vict. Motsch. MIém. de la Soc. des nat. de Mosc., t. V, tab. xvi, fig. B.

Castaneo-cinnamomeus. Antennarum articulis tribus $5-4-5$ subaqualibus. Thorace posticè foveolato.

Ias. Femoribus et libiis intermediis intus dente instruclis.

\section{Long, 2 à 21 [4 mill.}

Cet insecte se rencontre dans toute l'Europe, et il vit en société avec de petites fourmis. Je l'ai pris aux environs de Paris avec la Formica nigra et aussi avec la Myrmica ccespitum. Je possède également quelques individus pris près de Loudun en société de la Formica flava. Il faut le chercher sous les pierres, dans les endroits arides et très-exposés au soleil. 


\section{Claviger colchicus.}

Vict. Motsch. Mém. de la soc. des Nat. de Mosc., t. V, tab. XVI, fig. A.

Castane-cinnamomeus. Antennarum articulo tertio obconico, duobus sequentibus paulo longiore. Thorace ad latera oblique compresso. Mas. femoribus el tibiis intermediis intùs dente instructis.

\section{Long. 23 [4 mill.}

En Géorgie, en société avec la Formica flava.

Il est très voisin du testaceus, mais il en diffère par sa taille un peu plus grande, ses antennes un peu plus longues et dont le troisième article est obconique et un peu plus long que les deux suivants; son corselet offre aussi de chaque côté, sur les flancs, une large dépression oblique, et présente à peinela trace d'une impression en dessus, près de la base.

3. Claviger longicornis.

Müller. In Germ. IIag., t. 3, p. 85.

Sturm. Cat. II ein. Ins. Sam.

Panz. Faun.-Ins, Eur., Fasc., 7.

Aubé. Monog. Pselaph., p. 62, tab. 94, fig. 2.

Clavifer longicornis. De Laporte. Hist. nat, des Anim. art., t. 1, p. 206.

Castaneo-cinnamomeus. Antennarum articulo tertio cylindraceo, sequentibus duobus mullo longiore. Thorace posticè foveola minutissima impresso ct ad latera oblique compresso.

IIas. Tibits intermedie inlis dente instructis, fombious mulicis.

Long. 23 [ 4 à 3 mill.

Cet insecte se trouve en France et en Saxe. Je pense 
qu'il doit se retrouver dans presque toute l'Europe, il s'agit de savoir le chercher. Il a été pris plusieurs fois dans les environs de Loudun et de Chinon (France centrale); et toujours en société avec la Formica flava.

\section{TROISIEME SECTION.}

Antennes d'un seul article.

\section{Articerus.}

Dalman. Om Ins. innes $i$ cop., p. 23.

Antennarum clava elongata, inarticulata. oculi distincli ad capitis latere sili. Tarsi brevissimi articulo ut videtur unico.

Dans l'intérieur de la résine copal.

Antennæ prorectæ, clava elongata, cylindrica, inarticulata, apice truncata. Oculi laterales distincti, prominuli. Habitus Clavigeri ore clauso; elytris dimidiatis; abdomine magno, marginato : genus memorabile ad coleopterorum finem forte ponendum, Clavigero antè nimis affine, sed distinctum antennarum clava aut vere inarticulata, aut articulis adeo saltem connatis, ut distingui haud queunt. Cum in Clavigero antenne constant articuli 6, inaqualibus, discretis et vale distinctis. Oculi in Articero valde conspicui, ad latera capitis siti; in Clavigero aut plane nulli, aut adeo oculati, ut nec oculatissimo Müllero, nec milii unquam successum in eorum rudimenta detegere. A Pselapho omnino distat Articerus, forma et antennarum et capitis atque tarsis aliter constructis.

Nomen ab Ascios integer et Xzprs cornu. (Dalman.)

\section{Articerus armatus.}

Dalman. Om Ins. innes i cop., p. 23, tab. 4, fig. 12. Aubé. Monog. Pselaph., p. 64, tab. 9', fig. 3. 
Ferrugineus. Antennarum clava cylindrica truncala longitudine capilis. Pedum intermediorum femoribus bidentalis. Tibiis unidentatis. (Dalman.)

\section{Articerus Fortnumi (1).}

\section{Hope. Ann. of nat. hist., vol. XI, p. 319.}

Sanguineus. Capite elongato ovato, fronte rolundalo. Thorace fere quadrato, angulis anticis rotundatis, medio impresso. Elytris thorace latioribus, marginibus posticis nigricantibus. Abdomen posticè rolundato, utrinque macula nigra insignato.

$$
\text { Long. } 1_{[}^{2} \text { lig. - Larg. } 1 \text { [ }^{4} \text { lig. (Hope). }
$$

\section{Rapporté de l'île Adélaïde par M. Fortnum.}

(1) Il est bien à regretter que $M$. Hope, ayant eu à sa disposition un individu du genre Articerus libre de toute entrave, ne soit pas revenu sur les caractères qui lui sont propres et qui n'ont pu qu'être entrevus par Dalman à travers le copal dans lequel était enfermé l'insecte sur lequel il a èté établi. M. Hope n'aurail-il pas du revenir sur la structure des antennes et des tarses que Dalman présume être uniarticulés. La confirmation de ce fait était cependant du plus haut intẻrêt. 


\title{
APPENDICE (1)。
}

\author{
Faronus (2).
}

Antennce moniliformes, gradatim vix clavale, in tuberculis frontalibus inserta. Palpi maxillares quadri-articulali, articulo ullimo ovoidali. Tarsi bi-unguiculali, unguiculis cequalibus.

Corps allongé et déprimé. Tête offrant un double tubercule frontal pour l'insertion des antennes, qui sont moniliformes et presque insensiblement renflées de.la base à l'extrémité; palpes maxillaires de quatre articles : le premier très-petit, le second allongé et en massue, le troisième assez pelit et triangulaire, le quatrième de médiocre volume, ovoïde et terminé par un petit appendice membraneux. Elytres déprimées. Abdomen déprimé et largement rebordé. Pattes assez longues; tarses de trois articles : les deux premiers très petits, le troisième beaucoup plus long que les deux précédents réunis et terminé par deux crochets égaux.

Ce genre qui doit être placé après les Batrisus a la plus grande analogie de forme avec le genre Euplectus, dont il diffère par l'insertion des antennes et par les tarses dont les deux premiers articles sont très-petits et le dernier terminé par deux crochets égaux ; les palpes maxillaires, à en juger par l'inspection à l'aide d'une simple loupe, sont en tout semblables à ceux des Euplectus.

(1) La partie de mon travall oủ sont clássés les Psélaphiens qui ont deux crochels aux tarses étant imprimée lors de la communication qui m'a èté faite de ce genre, j'ai du en faire le sujet d'un appendice.

(2) Nom sans aucune significalion. 
J'ai créé ce genre sur une seule espèce trouvée par M.le marquis de la Ferté-Sénectère en battant des fagots; il n'a lui-même rencontré qu'un seul individu de cet intéressant insecte et a eu l'extrême générosité de me le sacrifier.

\section{Faromus Lafertei.}

Caslaneo-cinnamomeus, antennis pedibusque dilutioribus. Capite picescente, utrinque post oculos uni-tuberculato.

\section{Long. 11,2 mill.}

Corps allongé et déprimé, d'un châtain un peu clair. Tête un peu plus foncée, portant en dessus et dans toute sa longueur deux petites côtes saillantes, longitudinales, presque parallèles, et terminées chacune en avant en une petite saillie arrondie, sous laquelle est insérée l'antenne; ces côtes sont séparées par un sillon très-profond, dans lequel on observe tout à fait en arrière un petít tubercule arrondi, un peu moins élevé que les côtes saillantes; elle offre, en outre, de chaque côté et en arrière des yeux, un autre petit tubercule pyramidal; antennes testacées et couvertes d'un duvet assez abondant; elles sont trèsinsensiblement renflées de la base à l'extrémilé, a vec le premier article assez long, le troisième sensiblement plus petit que le précédent et le suivant. Corselet cordiforme, rétréci en arrière, fortement arrondi sur les côtés, un peu avant le milieu; la base est coupée carrément; il est marqué en dessus et un peu au devant de la base de deux impressions longitudinales assez courtes, très-fortement enfoncées, plus étroites en avant qu'en arrière, où elles sont réunies entre elles par un sillon transversal; on ob- 
serve encure, tout à fait en dehor's et au devant des angles postérieurs, une autre impression inégalement arrondie et asscz enfoncée. Elytres à peine plus longues que le corselet, déprimées, un peu plusétroites en avant qu'en arrière et marquées d'une strie suturale et d'une autre strie qui, partant de la base, marche un peu obliquement de dehors en dedans jusqu'au quatre cinquième de leur longucur, où elle se réunit à la précédente; on observe encore tout à fait en delıors une petile dépression longitudinale. Abdomen très-largement rebordé, le premier segment de la longueur du suivant. Pattes testacées.

Trouvé près de Chinon par M. le marquis de la FertéSénectère, auquel j’ai cru devoir le dédier comme un témoignage de la recomnaissance que lui doit la science pour une découverte aussi intéressante.

Explication de la planche III .

$N^{\text {s }}$ 1. Organes buccaux du Metopias curculionoides.

2.

3.

4.

5.

6.

7.

8.

9.

10.

11.

12.
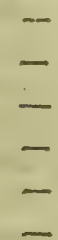

-

-

0.

1. - du Batrisus formicarius. du Tyrus mucronatus. du Chennium bituberculatum. du Cienites palpalis. du Pselaphus Heisei. du Bryaxis homatica. du Bythinus bulbifer. du Tychus niger. du Trimium brevicorne. de l'Euplectus signatus. du Glaviger testaceus. 


\section{EIEREAM.}

$\begin{array}{rrrl}\text { Page } & 74 \text { lig. } 32 \text { au lieu de } \text { Kafer. } & \text { lisez, } \text { Kcefer. } \\ 75 & 14 & \text { ctinistes } & \text { ctenistes } \\ 76 & 4 & \text { maxillaires } & \text { labiaux } \\ 78 & 20 & \text { fusiforme } & \text { fusiformi } \\ 78 & 21 & \text { I'lanch. VI. } & \text { Planch. III. } \\ 80 & 7 & \text { Planch. VI. } & \text { Planch. III. } \\ 85 & 29 & \text { Thoraec } & \text { Thorace } \\ 86 & 3 & \text { au milieu de la } & \text { au milieu d'un nid } \\ & & & \text { de la } \\ 87 & 30 & \text { le rapporter } & \text { la rapporter } \\ 91 & 5 & \text { arcutata } & \text { arcuata } \\ 92 & 5 & \text { latericius } & \text { lateritius } \\ 93 & 28 & \text { bipuntata } & \text { bipunctato } \\ 99 & 18 & \text { les palpalis } & \text { le palpalis } \\ 99 & 19 & \text { des palpalis } & \text { du palpalis } \\ 101 & 7 & \text { plus large } & \text { plus long } \\ 101 & 28 & \text { des Mark Brand., der Mark Brand., } \\ 102 & 27 & \text { des MarkBrand., der Mark Brand., } \\ 105 & 29 & \text { stenale } & \text { sternale } \\ 109 & 9 & \text { Zietsch. } & \text { Zeitsch. } \\ 109 & 14 & \text { semiarculari } & \text { semicirculari } \\ 110 & 19 & \text { plus longs } & \text { plus long } \\ 111 & 10 & \text { dilatioribus } & \text { dilulioribus } \\ 111 & 30 & \text { qui vient } & \text { et qui vient } \\ 114 & 6 & \text { abdomen } & \text { abdomine } \\ 127 & 3 & \text { très étroit } & \text { très étroitement } \\ 129 & 3 & \text { penestribus } & \text { pinestribus } \\ & & & \end{array}$




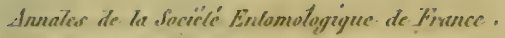

2e. Série - Tome II.PL.3.

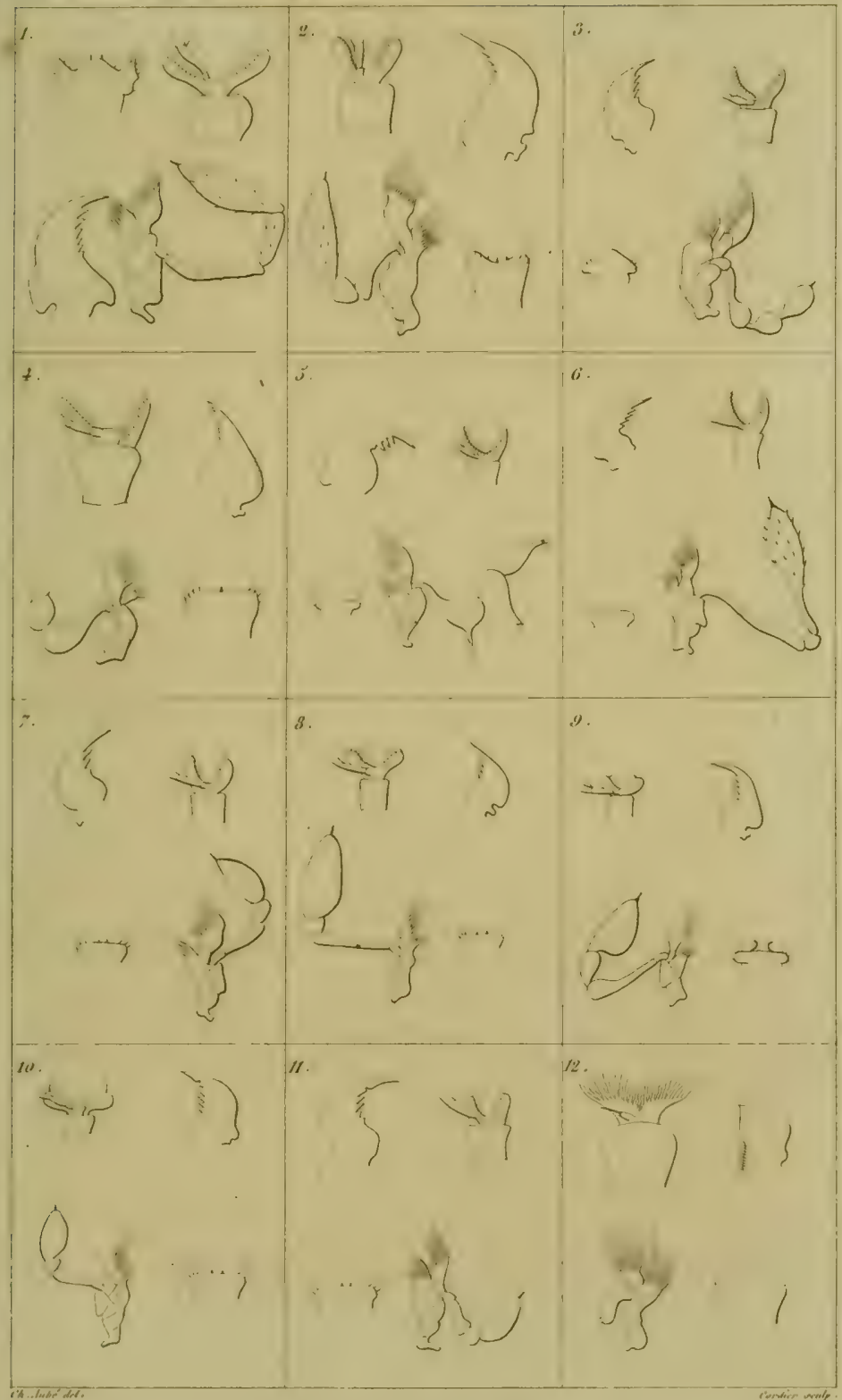

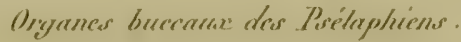




$z$

$z$

$z$

S SMITHSONIAN INSTITUTION NOIINIIISNI NHINOSHIIWS
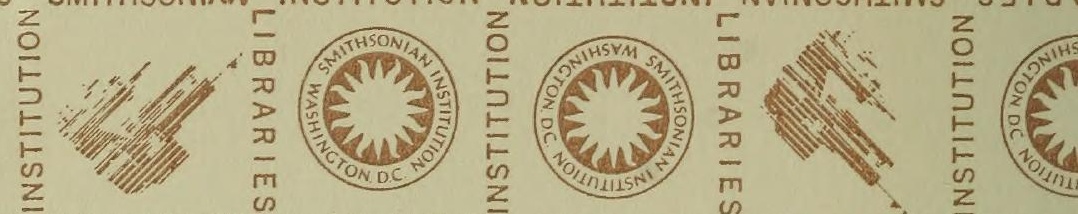

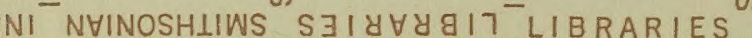

SMITHSONIAN INSTIT
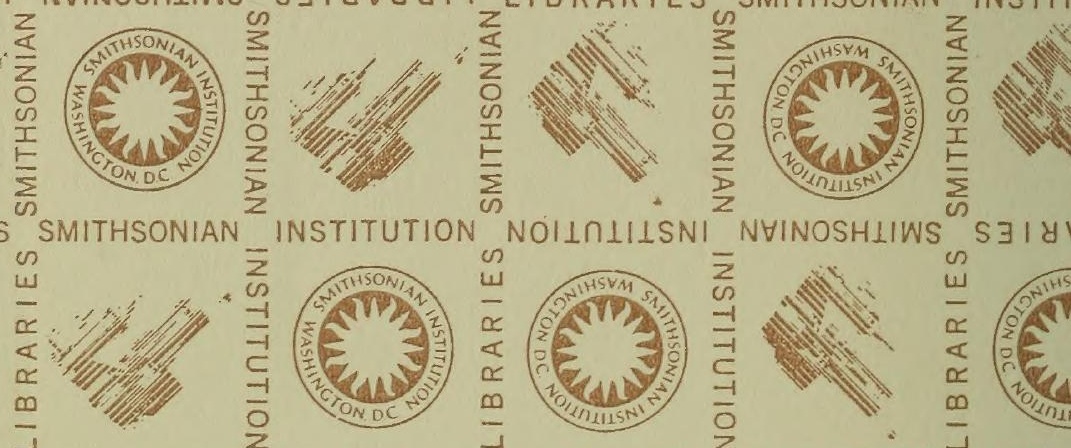

NHINOSHLIWS S $\exists \mid$ y

NI NHINOSHIIWS
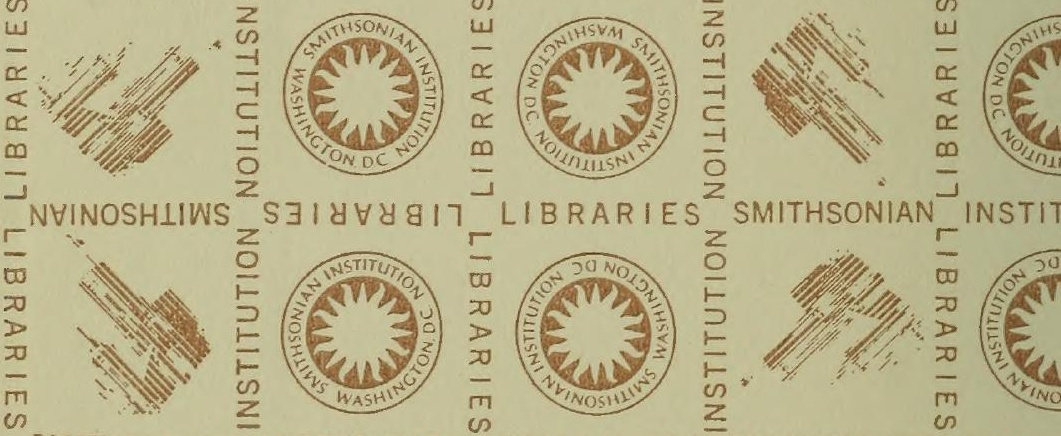

ES SMITHSONIAN

INSTITUTION
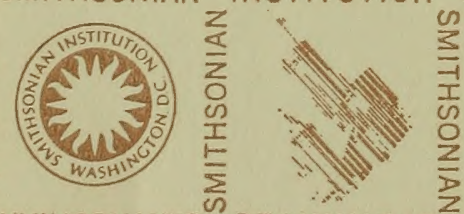

NOIINIIISN

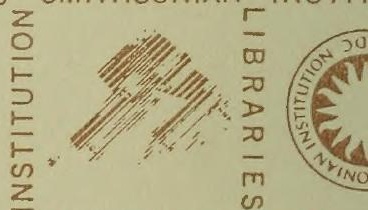

NVINOSHIIWS

$\overline{2}$
$=1$
$=$
$\bar{c}$
$\overline{0}$
2

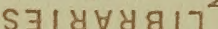
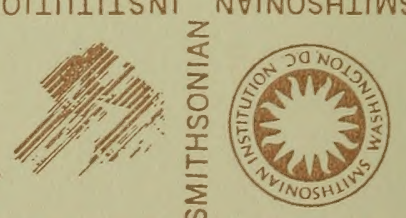

$\frac{n}{3}$

SMITHSONIAN INSTIT
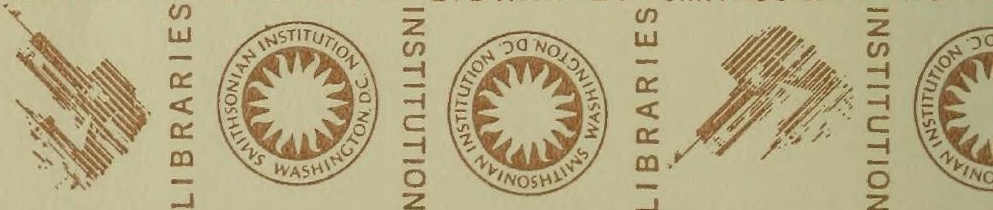

ES SMITHSONIAN

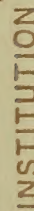

INSTITUTION

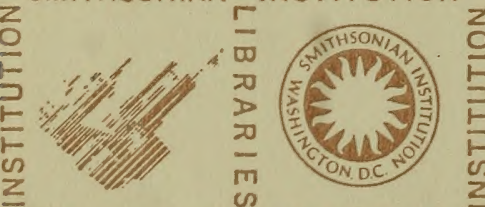

NOIIRIIISNI
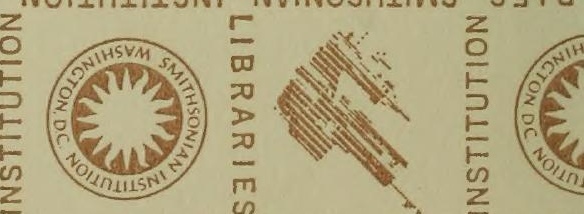

NI NHINOSHIIWS S I Y Y 
